\title{
AN EVALUATION OF A PRECOLLEGE PROGRAM ON COLLEGE SUCCESS
}

A Dissertation
presented to
the Faculty of the Graduate School
at the University of Missouri-Columbia
In Partial Fulfillment of the
Requirements for the Degree
Doctor of Education
MERILEE A. KRUEGER
Dr. Casandra Harper Morris, Dissertation Supervisor

December, 2020 


\section{DEDICATION}

This dissertation is dedicated to my family: First, to my parents, Jerry and Mary Ann

Krueger. You encouraged me throughout my entire life. You were my champions in everything I ever attempted and taught me to believe in myself.

For your unwavering support and everything you continue to do for me, I am forever grateful. To my sister, Cheryl Kolb and brother, Skip Krueger. You are a fundamental part of my life. We grew up together and now we are close friends. Thank you for adding humor to everything we do and generously including me in your lives and believing in me.

To my sons, Nicholas and Samuel Wilsdorf. You are such smart, independent, talented young men, and I feel fortunate to be your mother. I admire the hard work and determination you have shown throughout your lives especially right now as you continue your own educational pursuits. Thank you for inspiring me and teaching me what really matters in life.

Finally, to my husband, Dr. Jon Wilsdorf. I do not even know where to begin to express the love and admiration I have for you. You are the most valiant and resilient person I know, and I am proud to be your partner in life. I feel incredibly lucky that you have been by my side - not only through my desire to continue my education but always. I could not have done this without you. I love you. 


\section{ACKNOWLEDGEMENTS}

First and foremost, I want to thank Dr. Casandra Harper Morris. As my dissertation supervisor, you were everything I needed. You were my mentor, encourager, editor... I cannot thank you enough for the hours you spent meeting with me and assisting me with my dissertation. You challenged me to think critically and thoughtfully about my methodology and what I was trying to learn through my dissertation. Because of you, I have come to appreciate qualitative data analysis!

I also want to thank the members of my committee: Dr. Jennifer Fellabaum-Toston, Dr. Bradley Curs, Dr. Laura Page. Your guidance and encouragement helped me as both a scholar and practitioner.

I want to acknowledge the faculty members in my psychology department at Missouri University of Science and Technology, particularly our chair, Dr. Susan Murray. Everyone was incredibly supportive and allowed me the time and opportunity to discuss methods, statistics, and writing. Thank you to my classmates in Cohort 11, particularly those in Jefferson City with whom I learned to work "Off the Grid." Working with all of you challenged me and taught me so much. In particular, I want to thank Joanie Burch and Stephanie Martensen. Together we logged hundreds of miles going back and forth to Jefferson City each week. Our car discussions were an essential part of my education.

And finally, I wish to thank my dear friends, Lindy Hardwick and Debbie Priesmeyer. You provided me constant encouragement and support as we drank gallons of coffee every week. You helped me believe I could actually complete my dissertation. 


\section{TABLE OF CONTENTS}

ACKNOWLEDGEMENTS................................................................... ii

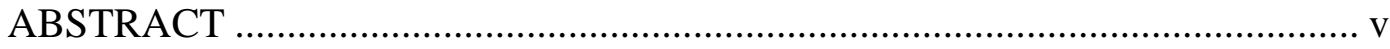

I. INTRODUCTION TO THE DISSERTATION-IN-PRACTICE ..............1

Background

Statement of the Problem

Purpose of the Study

Research Question

Conceptual Framework

Design of the Study

Limitations, Assumptions, and Design Controls

Definition of Key Terms

Significance of the Study

Summary

II. PRACTITIONER SETTING FOR THE STUDY ................................20

History of the Organization

Organizational Analysis

Leadership Analysis

Implications for Research in the Practitioner Setting

Summary

III. SCHOLARLY REVIEW FOR THE STUDY

Introduction

Review of Extant Scholarship Related to Study

Summary

IV. CONTRIBUTION TO PRACTICE

V. CONTRIBUTION TO SCHOLARSHIP .............................................55

VI. SCHOLARLY PRACTIONER REFLECTION ...................................75

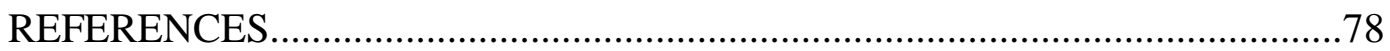

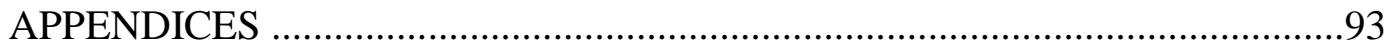

Appendix A - Interview Questions..................................................93

Appendix B - Email Script for Recruitment .......................................94

Appendix C - Institutional Review Board Approval............................ 95 
Appendix D - Letter of Support Letter - Office of Academic Affairs......97

Appendix E - Organizational Chart Missouri University of Science and

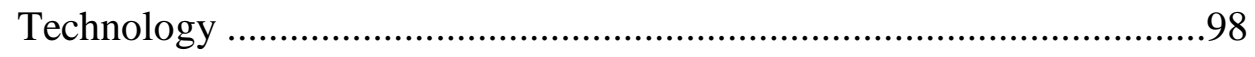

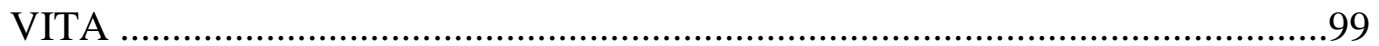




\begin{abstract}
The purpose of this study was to investigate the impact of a precollege summer program at Missouri University of Science and Technology known as Hit the Ground Running (HGR). It used a convergent mixed-methods research design, combining data from semi-structured interviews with HGR participants and institutional data on previous HGR participants (e.g., high school grades, ACT scores, math placement test scores, enrollment dates, graduation term). It was based on the theoretical frameworks of Vygotsky (1978) and Bandura (1997). Bandura proposes that self-efficacy is an important factor for college success. Vygotsky suggests that effective learning requires social interaction. While the study did not provide a comparison group, the quantitative data suggest that HGR is an effective program in term of graduation rate and retention. It also found that the primary reasons listed as to why HGR was helpful were that it facilitated the formation of friendship and increased their sense of preparedness, thus selfefficacy in college.
\end{abstract}

Keywords: Summer bridge programs, friendship, academic self-efficacy, academic success 


\section{SECTION I: INTRODUCTION TO THE DISSERTATION-IN-PRACTICE} An Evaluation of the Impact of a Precollege Program on College Success

\section{Background}

Earning a college degree can have multiple benefits. The average person in the United States with a college degree can expect to make almost twice as much as someone who graduated from high school (Doubleday, 2013). College graduates also have longer life expectancies than non-college graduates (Hummer \& Hernandez, 2013), and graduates also demonstrate higher-level reasoning and cognitive skills (Pascarella \& Terenzini, 1991); however, not everyone who begins college graduates. According to the National Center for Education Statistics (2018), only 59\% of students enrolled in college at a public institution earn their degree within six years.

Low graduation rates are of concern for all college students, but can be of particular concern for students who major in science, technology, engineering, and mathematics (STEM). This specific interest is because the workplace is changing. As STEM skills become more critical, the lower degree completion can have far-reaching effects on a person's employability. Without a STEM degree, person's competitive edge can be diminished (National Science Board, 2018). Not having a STEM degree can put students at a deficit because they do not have the required skill set necessary for employment in the current job market (Rothwell, 2013). Also, if students complete college with a non-STEM major, they may be less employable or earn less money (Russell \& Atwater, 2005). Graduates from STEM fields attain higher career earnings and social status positions than many other areas (Kokkelenberg \& Sinha, 2010).

Due to the increased demand for STEM in the workplace, there is a surge in students who begin college majoring in STEM, although approximately half of these students graduate with a degree in their original major (National Academies of Science, Engineering, and Medicine, 
2016). Some of these students change their majors, others leave the STEM fields, and some drop out of college altogether (Chen, 2013). It is essential to note that this low completion rate existed for many years as various researchers have found little change in this graduation rate in the past 60 years of study (Besterfield-Sacre, Altman, \& Shuman, 1997; Geisinger, \& Raman, 2010).

When students do not finish their degrees, this is problematic for colleges and universities as well. Not only do colleges lose tuition dollars from students who leave before graduation, but low degree completion rates can discourage potential students because they do not want to attend a school where few students graduate (Schneider \& Yin, 2011). As a result, colleges also want students to graduate. To that end, they are aware that it is essential to direct their efforts to increase graduation rates for students enrolled in their colleges (Vedder,2018).

Therefore, in response to the concern over low graduation rates in all fields, including STEM, universities have explored various ways to help students be successful and graduate from college (Jones \& Braxton, 2010). This dissertation in practice focused on the specific retention efforts of Missouri University of Science and Technology (MS\&T). MS\&T offers 20 STEMrelated degrees and even provides a STEM-focused-elementary education degree program (Missouri University of Science and Technology, n.d.). Thus, the university has a particular interest in student success in STEM fields.

For my dissertation in practice, I investigated the university's summer bridge program, Hit the Ground Running (HGR). This program prepares students for their first semester of college. It is a three-week program in the summer before the beginning of the student's first year. HGR is open to all students but strongly suggested for students who have lower than MS\&T's average ACT score or a low high school grade point average. Participants live oncampus and partake in classes and activities designed to help them get a positive perspective on college and instruction on learning and studying (Missouri University of Science and 
Technology, n.d.).

\section{Statement of Problem/Problem of Practice}

HGR has existed since the 1990s, but there has not been a formal investigation into its effectiveness. While students and faculty have given anecdotal reports that it works, there has been no specific analysis. When data are gathered and analyzed, it can help administrators make informed decisions (Datnow \& Park, 2014). Therefore, a problem of practice is that HGR has not been scientifically reviewed. There is no official data that link student outcomes to student participation.

\section{Purpose of the Study}

The purpose of this dissertation in practice was to examine the impact of MS\&T's bridge program, HGR. This research provides data for informing decisions about which programs receive resources and can advise institutional decision-making (Shen, \& Van Cooley, 2008). It will tell administrators of HGR that the program is useful and what exactly it provides to help students be successful. This research result influences my specific practice as a professor and advisor because I now know the factors contributing to student achievement. It also has the potential to contribute to the overall knowledge base of bridge programs at other universities.

\section{Research Question}

The study used a convergent mixed-methods research design, combining data from semistructured interviews with HGR participants and institutional data on previous HGR participants (e.g., high school grades, ACT scores, math placement test scores, enrollment dates, graduation term).The study addressed the following question: What is the benefit of participating in HGR? 


\section{Conceptual Framework}

Various frameworks could serve as the basis on which to evaluate research on student retention. The two of note for this academic evaluation are from Bandura (1997) and Vygotsky (1978). These were combined and formed the basis of the conceptual framework for this research. The reason behind introducing and utilizing a theoretical or conceptual framework in scholarly work is to provide an organizational starting point. It helps create a basis for the reader to understand why the research is important. It also helps establish the literature from a specific perspective (Ravitch \& Riggan, 2012). Thus, the reader can use this foundation for analysis and understanding of conducted research.

The reason for choosing the works of Bandura (1997) and Vygotsky (1978) was that this study was to help determine some of the factors that contribute to positive student outcomes. Bandura's theory proposed that a person will be more successful at a task when they believe in themselves. Hence, self-efficacy would seem to be a critical factor for being effective in college. I included Vygotsky's theory because he proposed that appropriate learning required social interaction. The summer bridge program's core involves being part of a learning community and participating in on-campus living and learning. Therefore, the two frameworks supported the idea that better learning occurs with others, which can increase one's confidence in doing well in college.

Consequently, the first framework on which this research was based came from the works of Bandura (1997). His theory relates to student success by proposing a link between having a positive belief in oneself and achievement. He suggested that a person's confidence about themselves influences their behavior and their ability to perform. In particular, he said that the extent to which someone has assurance in whether they can do something impacts their capacity to do the actions, which he called self-efficacy. Bandura put forward the idea that self-efficacy 
affects a person's choice of activities and their determination and perseverance at what they are doing. As a result, he said that someone with a high self-efficacy is much more likely to attempt something, whereas people with low self-efficacy may avoid even starting in the first place. Hence, participating in a pre-college program has the potential to impact self-efficacy.

Another tenet of Bandura's (1993) theory is that self-efficacy is shaped by receiving feedback on performance, which impacts motivation. He elaborated on this idea by saying that often assessing ability comes through social comparison rather than objective feedback.

Therefore, the person must see themselves as successful. Hence, helping students feel successful will be more effective if the student receives feedback on performance, and this can be a part of a pre-college program such as HGR.

Bandura and Jourdan (1991) also discussed self-efficacy in terms of feeling capable and proficient. They proposed that a person is likely to have a stronger sense of their abilities if they have positive experiences associated with their task. For example, suppose a student is taking a class. If they find it challenging they are more likely to retain confidence in their ability if they have had success in a previously situation. Therefore, a summer program can help create positive experiences, thus increasing confidence in academic ability. It is likely that the classes in a supplementary curriculum could offer mastery experiences and support the study.

Wood and Bandura (1989) also proposed that high self-efficacy is necessary if a person wants to enact a behavior change. In college, this could involve changing one's study habits or how to engage with academic material. Bandura stressed that any modifications depend on the perception of one's ability, and he proposed this is even more important than actual ability when it comes to actions. Therefore, having a strong sense of self-efficacy can impact their success, and a summer program can be the vehicle to enhance these feelings in students. 
The other theory that applies to this literature review, combined with Bandura, is Vygotsky's (1978) social learning theory. Vygotsky's theory states that learning is a social and cognitive process and that social interactions are essential. Based on this idea, Vygotsky outlines the specific ways a teacher directs a learner and says that individuals learn best when others teach them. He describes a teacher as the person who has more expertise in the subject than the learner. This person could be an adult or peer, but the key is to know more than the student and convey the desired knowledge. Vygotsky says when a person begins the learning process, they only have preliminary skills. He calls the place between what the learner knows currently and where they want to be as the zone of proximal development (ZPD). The tutor's job is to help the person get beyond the ZPD and gain more advanced knowledge. Vygotsky says that through this student-teacher interaction, the student creates their own understanding, and the interface is vital because it allows the teacher to gauge what the learner knows.

Vygotsky (1978) says this hands-on guidance is part of the social interaction of instruction. Because the process is social and interactive, the teacher can know when to supplement what the person is learning and let them figure things out. Vygotsky called this assistance scaffolding. Just as a builder needs to provide supports while constructing a house, so does the tutor with the student. Through this social interaction, the tutor knows how much help to offer at the right time.

Educators have applied Vygotsky's theories to learning environments in all age groups, including colleges. Hausfather (1996) used Vygotsky's ideas in school settings and found that when students work in a social situation, they are more likely to increase their cognitive ability. This finding was also supported by other researchers who found that student learning is cultivated in settings with appropriate levels of support and challenges in a learning environment (Thompson, 1999). 
Hence, I combined Vygotsky's (1978) theory of social assistance with Bandura's (1997) framework. To reiterate, Bandura contends that one must believe they can do what is necessary to be successful. Vygotsky says that successful learning requires appropriate assistance. Receiving appropriate aid in a social context supports Vygotsky because tutors and professors guide students to the next level through social interaction. The setting in which the person is learning determined that content was essential. So, if a student has a goal of majoring in engineering (or any major), to be involved, he or she must learn the basics of those classes, and Vygotsky would say the best way to do this is collaboration. HGR allows students to increase self-efficacy feelings within the context of learning with other students in a supported environment. Partaking in classes, tutoring, and living with others can increase the student's ability to do well in college.

Therefore, this research aimed to discover what role the HGR program played in helping students be successful and complete college. I defined success as graduating within 6 years of beginning college. Graduation was measured quantitatively to record whether or not the person graduated. However, the dataset I used only had a 6-year graduation rate for one summer bridge class. Another quantitative comparison was to see if completing the summer program correlated with higher math placement scores. As the summer program is multi-faceted and is more than numbers, I also collected qualitative data to measure the extent to which the pre-college curriculum affected self-efficacy and motivation. I collected this data via interviews with students who participated in the program. In particular, I asked them a variety of questions so they could discuss their experiences with HGR impacted them.

This sense of confidence is tied to Bandura's (1997) research, which states that belief in oneself increases performance. I based other questions in the interviews on Vygotsky (1978) and his idea that enhanced learning occurs in a social context. I asked participants to discuss the 
interactive component of their summer experiences. In particular, I questioned them about their instruction and their interactions while participating in HGR. I inquired as to the impact of how working with other students, faculty, and additional tutors, while living in a learning community on campus, contributed to their perceived sense of achievement. A full list of questions can be found in Appendix A.

\section{Design of the Study}

Setting. The study took place on the campus of Missouri University of Science and Technology. I completed a program review of the university's summer bridge program, Hit the Ground Running (HGR) focusing on a 6-year time frame.

Participants. The participants in this study came from a convenience sample. The data were part of a pre-existing database I received from the Office of Academic Support and contained students who completed HGR between the summers of 2014 and 2019. My access to data did not allow for a control group comparison. According to Jeff Cawfield, former Vice Provost of Academic Support, the attendance and performance information has been "collected for years, but not much has been done with it" (personal communication, February 21, 2019). Consequently, archival information was analyzed to answer the stated research questions from a quantitative perspective. The time frame included in this study began with students who matriculated at MS\&T in 2014 and each subsequent year until 2019. The rationale behind looking at this time frame is in line with graduation rates defined by the Integrated Postsecondary Education Data System (IPEDS) classification. Their definition is based on the number of full-time, first-time, degree-seeking students who start and finish at the same institution (IPEDS Glossary, n.d.).

Since this study's objective was to find a relationship between the summer bridge program at MS\&T and graduation, I used one 6-year group. It would have been preferable to 
have more than one cohort, but I had to balance the available data with whether or not I could locate students for interviews. I was concerned that if I included students from earlier groups, I would be less likely to contact them.

For the qualitative component of the study, I conducted semi-structured interviews with students who completed HGR. I chose students randomly from the participant list. This method used a purposeful, convenience sampling to give me various stories from participants (Creswell, 2014). I received a list of 448 students who participated in HGR in the summer of 2014 until summer 2019. I sorted the participants for each summer enrollment date. Please see Table 1 for the distribution per year.

\begin{tabular}{|c|c|c|c|c|c|c|}
\hline Year & 2014 & 2015 & 2016 & 2017 & 2018 & 2019 \\
\hline Students & 60 & 91 & 81 & 75 & 78 & 66 \\
\hline
\end{tabular}

Table 1: HGR Enrollment Sorted by Year

Data Collection Tools. All procedures for this research were submitted to and approved by the IRB at the University of Missouri - Columbia campus (Appendix C). I also obtained a letter from the MS\&T Office of Academic Support, granting me permission to use the data from HGR (Appendix D). I removed all identifying information from the data set and assigned each student a number. I did this to ensure I conducted ethical research, as recommended by Creswell (2014). The data set included a high school GPA, ACT score, and a university completion date. I also had math placement test scores from both before and after participation in the summer program. Two math placement test are given to students when they come to campus to register for classes, and their score determines which math class in which they will enroll when they begin classes. Both scores were in this dataset. 
For the qualitative data collection, I used a random number generator to choose students to contact for an interview. Students were contacted by e-mail and asked for their participation. The e-mail also gave them a brief explanation of the end goal of my study. If the person did not have a current e-mail at the university, I went to the next person on the list. Please refer to Appendix B to see content of the invitation e-mail.

I offered interviewees a \$20 Amazon gift card for their participation. This payment served as a way to show my appreciation for taking the time to give an interview. While there is debate regarding the ethical practice of paying people to participate in qualitative research, the general guideline seems to be that if the amount is reasonable, it is acceptable (Head, 2009). Therefore, I chose the amount based on the idea that it was small compensation for the participant but not so large as to be considered coercive.

The semi-structured interviews were approximately 30 minutes, as this was a commonly recommended time limit for interviews (Merriam \& Tisdell, 2017; Seidman, 2013). I recorded these interviews and also took written notes. Conversations were documented with the audio recording device on Zoom and participants all gave verbal permission to be recorded. It is important to note that I conducted interviews in the spring and summer of 2020 , so due to COVID-19, I could not interview students in person as I had initially planned. Instead, I amended my IRB application and included the possibility that I would interview students via Zoom. Students were free to choose the time of their interview.

Data Analysis. In this study, I used a convergent mixed-method design. I analyzed the qualitative and quantitative data at the same time. This technique allowed both methods to complement and enhance each other, thus providing a deeper understanding of the HGR program (Moseholm \& Fetter, 2017). The data were from a pre-existing database I received from the 
Office of Academic Support and contained students who completed HGR between 2014 and 2019, so this design did not provide a control group. The data included high school grade point average (GPA) and ACT scores for all students participating in HGR. It also listed dates of completion, as well as pre and post math placement scores. I combined the descriptive statistics along with data from semi-structured interviews with HGR participants to address the following research question: What is the benefit of participating in HGR?

The data analyzed for this study were limited to a subsample of students who chose to participate in HGR. It is important to note that the quantitative data offered descriptive, not causal, program effectiveness comparisons. Descriptive statistics were calculated for various aspects of HGR. These calculations included the average ACT score and the average high school (GPA) for all participants. I also looked at changes in math placement scores. One of these tests is the Missouri Math Placement Test (MMPT). It is a 40-question, multiple-choice algebra placement test. The second test is a trigonometry placement test that is a 25 -question multiple-choice exam. A paired sample t-test was conducted for both of these tests to see if this difference in scores after participating in HGR was significant. Graduation and retention rates were also calculated.

When analyzing qualitative data, Merriam and Tisdell (2016) advise that data collection and data analysis occur simultaneously. Therefore, as soon as possible after an interview, I transcribed what the participant said. I did this by using both the recording mechanism in Zoom and notes. My written notes included the impressions and observations I had as the student answered questions. After I completed an interview, I summarized what was said and sent this information via e-mail to each participant to see if my assessment was accurate. If they did suggest some changes, I included these in the analysis. All participants were given pseudonyms. 
I also engaged in simultaneous data collection and analysis by reviewing interview transcripts and looking for recurrent themes. I did this by hand using different color highlighters for each term. As a result of this process, I saw the word friendship or friend in every interview transcript. Once I noticed this in the data, I went back to my interview write-ups and used the control F function to search for the word "friend," This technique showed me that every interview contained some variation of the word friend in response to why they felt HGR was helpful.

Searching for the word friend and related ideas helped me recognize when I had enough interviews to conclude data collection. When starting qualitative data collection, the specific number of participants is unknown at the onset. Instead, the recommendation is to collect responses reach one reaches saturation. Saturation occurs when the students' answers no longer give unique or novel information (Seidman, 2013). Therefore, I ended my data collection after I interviewed 12 participants.

As the primary researcher, I observed everything about the interview, not just the words. I took careful notes about my feelings as they occurred to me during the meeting. I looked for answers that related to how this summer program impacted them when they started their classes. The interviews added details I could not find with quantitative information only. They gave me a context, and I heard specific stories that facilitated my understanding of what exactly HGR did for them to prepare them to begin college. Also, while interviewing, I was mindful that it is vital to establish rapport because this is critical to accurate data collection. It can take many forms but what I did was I listened intently and focused my attention solely on each participant (Siedman, 2013). I began each discussion formally and displayed recommended courtesies, such as allowing them to choose the date and time, and I reiterated the meeting's purpose. The reason for giving them a choice was to increase their sense of control and comfort (Elwood \& Martin, 
2000).

After I finished each interview, I examined and coded the responses. I also summarized what was said and sent this information via e-mail to each participant to see if my assessment was accurate. None of the participants said that my summary was incorrect. If they did suggest some changes, I included these in the evaluation. During the data examination, I looked for patterns and themes. I mainly looked for words and topics related to the participants' experiences with HGR. Once I began to study the transcripts, I detected words like friendship and connections with other people. Upon closer investigation, terms of this sort were in every conversation. This finding led me to identify an important theme; friendship. Everyone said that meeting people and working with them was essential to their perseverance and achievement once they started classes. These friends and connections included fellow students, tutors, and faculty members.

The second theme I found was students said participating in HGR helped them know what to expect in college. They referred to having more confidence in their abilities because of what they learned about the requirements at MS\&T. While they also said it was stressful, it was common for them to say it was an essential precursor to handling the rigor of what was required. I further scrutinized the statements and added detailed explanations with thick descriptions. I recounted what respondents told me about their experiences and feeling and concluded they felt more ready to handle the upcoming academic demands (Merriam \& Tisdell, 2016). These methods helped my readers view the study as credible and trustworthy (Tracy, 2010).

\section{Limitations, Assumptions, and Design Controls}

One of the limitations of this study for my dissertation in practice is that it is almost impossible to assign students to participate in HGR randomly. Therefore, I did not have a control group with whom I could compare HGR results. I did calculate descriptive statistics for 
the program since there is no previous formal report. Hence, I cannot claim any causative element relating to graduation or success for HGR students.

Yet another limitation is that I did not have access to students no longer enrolled at MS\&T. These are students who participated in HGR but left the university before graduation. While I used their data in the quantitative statistical analysis of this dissertation, I do not have their stories. Interviewing the students who did not graduate from this university would add another layer of information. They might provide insights into why they did not remain at the university and if the summer bridge program played any part in their decision. Unfortunately, since I did not have access to them, their stories were not included because they are no longer accessible through the university's database.

An essential assumption of this research is that participants will answer honestly in their interviews. Honestly is critical to the proposed study because the responses will supplement the quantitative data and understand how HGR impacted them. If the answers are not truthful, then my research would not offer accurate insights and have reduced credibility. I tried to encourage honesty and reassure the participants that their responses will be kept confidential. Also, I told participants they could withdraw at any time, and if they did not want to answer a question, they could do so. Hopefully, these measures discouraged them from giving inaccurate answers if they were uncomfortable.

Another potential limitation is that I went into this research believing HGR is a useful program. I tried to be mindful of this belief and not project my opinion onto the responders. I understand that bias is inherent to human research, so it cannot be eliminated, but must be acknowledged (Merriam \& Tisdell, 2016). However, my belief in HGR is what initially sparked my interest in this research project. Thus, since I was the only person conducting the interviews, 
my positive view of this program was consistent through each meeting; thus, my presence and bias were the same throughout.

\section{Definitions of Key Terms}

This dissertation in practice used various terms and phrases. This section provides descriptions of the following keywords and phrases; Summer Bridge Programs, STEM, 6 Year Graduation Rate, Academic Self-Efficacy, and Academic Success.

Summer bridge programs were defined as residential programs in which students enroll before they begin college in the fall (Ashley, Cooper, Cala \& Brownell, 2017; Relles \& Tierney, 2014). STEM will be referenced often in this dissertation. STEM is the acronym used to refer to courses that focus on science, technology, engineering, and mathematics. The term STEM was first presented by the U.S. National Science Foundation (NSF) in 2001.

6-Year Graduation Rate is used by the Integrated Postsecondary Education Data System (IPEDS) classification system to report institutional data. Each year IPEDS publishes the results from surveys conducted annually by the U.S. Department of Education's National Center for Education Statistics (NCES). IPEDS reports statistics for all colleges and universities that participate in the federal student financial aid programs. This graduation rate was the percentage of first-time, full-time undergraduate students who began seeking a bachelor's degree at 4-year degree-granting institutions graduate within 6 years of matriculation at a specific institution (IPEDS Glossary, n.d.).

Academic self-efficacy was referred to as a student's mindset or belief that they can complete a task or goal related to their education (Bandura, 1997). Self-efficacy was individually determined for each student as each person had a unique perspective on their persistence level.

Similarly, academic success used the definition provided by York, Gibson, and Rankin 
(2015). Their description is multifaceted and includes such factors as a student's persistence in college that leads to graduation and, ultimately, the ability to be employed when they complete college.

While York, Gibson, and Rankin (2015) have various scales they use to measure student success, for my dissertation, the definition was provided by each student and their report of their college performance.

\section{Significance of the Study}

Contribution to Scholarship. Retention is considered a priority for most colleges (Schneider \& Yin, 2011), so to address this issue, universities are investing time and resources to do what they can to help students succeed. One specific strategy many are offering is pre-college programs (Ashley, Cooper, Cala, \& Brownell, 2017). Consequently, I was interested to see what type of impact our summer bridge program had on our students at Missouri University of Science and Technology. When I began my investigation, I learned that no formal report had been done to measure outcomes. I then explored the literature to see what was available for other programs and found similar results. While there are reports of individual programs, very few articles present a comprehensive literature review, particularly for STEM programs (Sablan, 2014). Even though this research was not be a complete literature review, it can shed light on what works in this specific program on this particular campus.

Using a mixed-methods approach to study this program is another important contribution to this data base. Very few studies talked directly to students about what made a summer program successful. They used surveys and other empirical means of measuring outcomes, no one gathered data through interviews. Even though Wolf-Wendel, Tuttle, and Keller-Wolfe (1999) conducted focus groups, individual accounts were not used for analysis. The stories from the participants provides a deeper explanation (Seidman, 2013) and I was able to get specific 
information about HGR. Consequently, this information can help guide future programs to include those elements students found to be so valuable.

The qualitative component of this research will help determine what makes HGR successful. Just stating numbers without fulling understanding their meaning is only part of the story (Shen \& Cooley, 2008). Therefore, the personal accounts I got from interviewers will help me see what students think is most helpful. I hope they can provide a deeper understanding of HGR, contributing to the database of bridge programs and other retention efforts.

Contribution to Practice. HGR has existed since the 1990s, but there is no official report on how it impacts students. According to Datnow and Park (2014), data can and should be used to help colleges make informed decisions. Therefore, one of the primary contributions to my practice is to give data to Missouri University of Science and Technology to help them see the effectiveness of HGR. This study can connect student participation with positive outcomes. This study can also inform my role as a recruiter and advisor. Part of my job is meeting with prospective students. During those meetings, students and parents will often ask about how to be successful at Missouri University of Science and Technology. I currently list the various resources our campus has to offer, but I do not have accompanying data to let them know how effective it is. Having the data for HGR will allow me to guide students to the right resources. Another contribution to my scholarly practice is informed decision-making. As money becomes less available, and the university decides on its budgets, administrators must know what produces positive results (Gagliardi, Parnell, \& Carpenter-Hubin, 2018). Therefore, the data from this study can be used to determine resource allocation. The proposed research will measure what works for HGR, and then these themes can be expanded in other campus resources as well. As a faculty member and advisor, this study's results can be an asset to both of these practices. 
On the recommendation of my dissertation advisor, I keep a note on my desk that says, "What do I need to know to help students be successful?" The results of this study will help me answer that question. When I see what HGR provides, not only can I recommend it to future incoming students can apply these findings to my advising and teaching.

\section{Summary}

In summary, it has been shown that there is an increased need for individuals to be educated in STEM fields (National Science Board, 2018). At the same time, there is a discrepancy between those who start STEM majors and those who earn their degree. While universities recognize this as a problem, the solution is multifaceted. As the literature shows, various approaches have been tried to find the answer to retention problems, but the investigation is ongoing (Graham, et.al. 2013).

This research contributes to the knowledge base on student retention and in particular the information on bridge programs. It revealed evidence of the effectiveness of the bridge program at Missouri University of Science and Technology and revealed aspects of the program that are working. It utilized both qualitative and quantitative evidence by using a convergent mixedmethod design. The quantitative data were used for descriptive comparisons from the preexisting dataset, while the qualitative data were drawn from semi-structured interviews with past participants from the program. However, this design did not have a control group so the data do not imply a cause and effect relationship, but serve onto describe the program.

The research was informed by the combination of two theoretical frameworks and drew from the works of Vygotsky (1978) and Bandura (1997). Vygotsky's theory states that learning is enhanced when it is part of a social interaction, while Bandura's research states that a sense of self confidence, or self-efficacy is important for increasing academic performance. These frameworks support the idea that a student will be able to achieve more by engaging with the 
other people and prepare them for the rigors of academia. This research offers empirical support for HGR and the ways in which participants have found it to be helpful. This research can provide students, professors, advisors, and administrators with a more careful analysis of HGR than has been previously conducted. I hope this study can contribute to the literature base on retention and help Missouri University of Science and Technology make positive changes to support the success of all students. 


\section{SECTION II: PRACTITIONER SETTING FOR THE STUDY}

The purpose of a dissertation in practice is to examine a problem or issue at a specific institution (Storey, Caskey, Hesbol, Marshall, Maughan \& Dolan, 2015). Therefore, to help readers understand my research, I provided some background about my university and the specific program I plan to study. This section offers information about Missouri University of Science and Technology and the HGR. It will provide a history as well as an organizational analysis for both. These will help the reader understand why I chose this project and the potential benefits this study will provide me as a scholarly practitioner.

\section{History of the Organization}

Missouri University of Science and Technology (Missouri S\&T; MS\&T) was founded in 1870 as the Missouri School of Mines and Metallurgy. The primary focus of the college when it began was to educate mining engineers and surveyors. It is located in Rolla, MO, and is now one of four campuses included in the University of Missouri System. In 1963, the University of Missouri System added schools in Kansas City and St. Louis. These were in addition to the main campus in Columbia. Then, in 1963, Missouri School of Mines and Metallurgy was added to the Missouri system, and its name changed to the University of Missouri at Rolla. In 1968, the name changed again to the University of Missouri-Rolla. This variation aligned the Rolla school with the other three campuses' names, explicitly referring to them as the University of Missouri followed by the city in which it is located. Yet another name change occurred in 2018 to the current name of Missouri University of Science and Technology. The rationale for this new name was that the administration wanted the title to more accurately publicize the university's focus, that it is a technological school. 


\section{History of Hit the Ground Running}

My study examined at a particular program offered at Missouri University of Science and Technology targeted at student success. Specifically, I studied the summer bridge program known as Hit the Ground Running (HGR). This program was to help students prepare for college. Its main objective was to give students realistic college experience, both academically and socially (H. Collier, personal communication, October 21, 2019). Since its inception, HGR requires students to live on campus, which exposes them to some of the college courses' demands. In particular, they take classes considered challenging to university freshmen, namely chemistry and mathematics.

HGR began in a different form before it evolved into its current state. In 1974, the Minority Engineering Program (MEP) implemented a Summer Enrichment Program for students of color. It began when a group of faculty members and the Association for Black Students developed a plan to bring more minority students to campus. This effort included a scholarship program and support of various engineering industries (Christensen, \& Ridley, 1983). MEP was a seven-week program designed to enhance the math, science, and English skills for these recruited students. When they completed the program, they were awarded a one-year scholarship to the university. Then, in the early 1990s, the money became a four-year award (H. Collier, personal communication, October 21, 2019).

In the 1990s, Hit the Ground Running (HGR) began. Administrators wanted a pre-college program available to all entering freshman, not just for minority students. MEP continued to exist and still focused on minority students. HGR began as a three-week program open to all students, and MEP remained a seven-week program, for students of color. The curriculums for the two programs were the same and consisted of four courses. These classes were math, 
English, chemistry, and a course in student success.

Both programs continued separately until 2005 when MEP and HGR merged into one. It was still primarily for minority students, and the scholarship money remained, but other students could also participate in the courses. The program took the title Hit the Ground Running and implemented the three-week curriculum. They chose a shorter format to see if students would have the same outcome after three weeks instead of seven. This change occurred for practical reasons. The program administrator reported the seven-week summer session created a significant summer workload for faculty, making staffing became a problem, so they compressed the program. Administrators did make sure the program was still valid even though it ran for less time. They considered it successful when these students' midterm grades showed only one student received an academic alert. This small amount of academic difficulties was in addition to reports from professors that said the students from HGR were academically ahead of their peers (H. Collier, personal communication, October 21, 2019).

Hit the Ground Running is currently housed in the department of academic support and the assistant vice provost of academic support manages it. There are various sub-departments in this office, and HGR is one of the College Transition Programs. Other programs managed by this department include the Honors Academy for the university, Learning Enhancement Across Disciplines (LEAD), and the Student Support Center. All of these are student-focused and aimed at increasing student success.

\section{Organizational Analysis}

Another essential part of providing context for my DiP is to give information for a deeper understanding of Missouri University of Science and Technology and HGR. To do this, I chose the four frames outlined by Bolman and Deal (2013). These frames are structural, human resources, political and symbolic. From this perspective, it becomes clear that organizations are 
multifaceted and complicated, and as a result, can be a challenge to manage (Bolman \& Deal, 2013). The purpose of this section is to help the reader understand the landscape of this university and how it can influence the retention program, HGR. I will also include the organizational structure and leadership of HGR.

\section{Structural Frame}

From the perspective of a structural frame, Bolman and Deal (2013) propose that all organizations have some structure. Still, it depends on the organization's type as to which model works best, and a university is a particular case. Missouri University of Science and Technology is part of the University of Missouri System. There is a president who oversees all four campuses; however, each school has an individual administration. Specifically, there is a chancellor at Missouri S \& T and a provost/executive vice chancellor for academic affairs who reports directly to the chancellor. On the academic side, there is also a dean/vice-provost of the college of arts, science and business and a dean/vice-provost of the college of engineering and computing, both of whom report directly to the provost/executive vice-chancellor. Other divisions under the supervision of the provost/ executive vice chancellor for academic affairs include the dean/vice-provost of enrollment management, the vice-provost for academic support, and the vice-provost for global learning.

Additional departments on campus report directly to the chancellor and are in charge of non-academic areas on campus. These include a chief diversity officer, a vice-chancellor for finance and operations, an executive director of marketing and communications, a vicechancellor for university advancement, and a vice-chancellor for student affairs. There is also a vicechancellor of research/dean of graduate studies who works directly with the provost. The specifics of this organization can are in the organizational chart. (Appendix E). 
Another critical structural division at Missouri S\&T is that it has two colleges. There is the College of Engineering and Computing (CEC) and the College of Arts, Sciences, and Business (CASB). While there are two separate academic units, it is necessary to note that most students who attend this university major in computing and engineering. Therefore, a great deal of the structural emphasis is in this college. This division is evident in the buildings on campus — most of the academic buildings house engineering and computer science. While in CASB, the sciences (physics, chemistry, and biology) and math have individual buildings, English, history, and psychology share one building, and business shares space with nuclear engineering. Therefore, just by looking at a university map, the structural emphasis of the dominance of engineering is apparent.

Another structural difference is in the number of students in each college. In the most recent freshmen class of 2019, 1178 total students enrolled at the university. Of those students, 972 declared their major to be some type of engineering or computer science. While this number will likely change as students continue in their studies, the vast majority of students on campus are in CEC (Missouri University of Science and Technology (n.d.).

Like most universities, the management of Missouri S\&T is a hierarchy, and sometimes this creates unique structural challenges. Specifically, this means that universities do not operate in the same way as businesses in the private sector. Different rules apply. In particular, tenured faculty members have a high degree of job security, and administrators cannot terminate them "at-will" as can happen in business (Saltzman, 2011). Since a large share of the employees is faculty, their voice is a crucial element. Specifically, faculty may not feel a top-down approach should rule them, but instead expect input into their governance (Manning, 2013). This mindset may create some difficulties for those in supervisory roles in academia. Administrators at all levels need to find a way to run a successful university while allowing genuine involvement from 
its faculty. Faculty Senate is one way that faculty have input into their governance. This body oversees multiple aspects of campus that impact the wellbeing of faculty and students (Missouri University of Science and Technology, n.d.). One of which is an established special committee for student success. HGR is a priority in this committee with the budget commitment of $\$ 100,000$ in funding (Missouri University of Science and Technology, 2016).

Everyone sees an educational setting from a personal point of view (Levi, 2017), so it imperative that an organization recognizes this and does its best to understand the people's diverse needs and motivations in the organization. When MS\&T established HGR as a precollege program, this was an effort to help students get a positive start to college. There are scholarships available but are limited to a budget of $\$ 25,000$. Scholarships are awarded based on a student's math placement score, their ACT score, and their estimated family contribution (EFC)) from the Free Application for Federal Student Aid (FAFSA). For example, if a student's test score placed them in Fundamentals of Algebra, they had an EFC of 0, and a low ACT score, they could attend HGR at no cost. Each year, the students who participate differ in their ability and financial need, and there is a limited amount of money available. Therefore, the amount given each year depends on the students requesting scholarships. If there are many students requiring aid, there is less money available, thus reducing the awards. It is important to note that the scholarships are not for the high achieving students, but rather are aimed at students who need extra help in academics and have financial need (R. Morris, personal communication, October 2019).

\section{Human Resource Frame}

Organizations are more than abstract hierarchies and structures; they consist of people, which is the basis of the human resource frame. According to Bolman and Deal (2013), analysis from this viewpoint suggests that a company's management needs to consider people as its most 
valuable asset and treat them as such. There are various types of people at a university, namely, students, faculty, and staff. Students are a vital component of a university, as they are necessary for the university to exist, and Shapiro \& Stefkovich (2016) suggest that the educational system's primary goal is doing what is best for its students. They expanded further, saying not only should the university be student-focused, but it is also an ethical responsibility of an educating body to put students at the forefront of every decision and policy.

The existence of a supplemental program like HGR demonstrates a sense of caring toward students. According to Bolman and Deal (2013), human resource is the part that attends to the needs of its people. In the case of a university, this translates to students, and HGR is to help. Its stated goal is to support learners and to be successful during their first year of college (H. Collier, personal communication, October 21, 2019). Hence, this program gives evidence that assisting students is essential. It conveys this message by making resources available that prioritize students and ensure they start college on a positive note.

Another component of the human resources frame is whether organizations commit to promoting their leaders from within the existing organization (Bolman \& Deal, 2013). HGR is an example of this philosophy. The vice provost of academic support is a tenured professor in geological engineering on campus. During his teaching and researching career, he also devoted a great deal of time working to increase undergraduate success and continued that role as a vice provost. His assistant, who is officially in charge of HGR, earned her master's degree from the university when it was UMR and has been a staff member on campus for 22 years. Both of these internal hires emphasize that not only is student success significant, so are people. When the university needed someone to take over HGR, administrators chose people who demonstrated a real commitment to its students' overtime and trusted them to oversee the program. The university invested in the effort to care for students. 
A commitment to diversity is also considered a part of the human resource frame. While the university has a strong commitment to diversity and has an entire department devoted to institutional equity, diversity, and inclusion office, this is not the direction in which HGR is going. As noted, the original summer program was to increase the success of minority students; however, that focus no longer exists. Bolman and Deal (2013) caution against actions that limit diversity in an organization because it may create a negative message about acceptance of all groups. Potential and current students may feel distanced from the university as a result.

\section{Political Frame}

Politics are a vital part of all organizations and determined their power structure. Those in power make most of the decisions and exert the most influence. Therefore, it is essential to note that not every group has an equal opportunity to be influential. At MS\&T, engineering majors and the college of computing and engineering wields the most power. These departments produce the most research and grant revenue and have the highest numbers of faculty, staff, and students (Missouri University of Science and Technology, n. d.). This power differential can be problematic because one group potentially dominates decision-making (Johnson, 2018). He goes on to say the situation is even more complicated when people remain silent when they see someone denied power because they belong to a specific group based on their race, disability, gender, or at MS\&T being in a non-STEM field. When no one challenges a situation, the status quo continues, and those in power remain, and there is little potential for change. HGR was an attempt to help minority students have a positive start to college, thus increasing their chances of graduating. Johnson proposes that supplemental programs like these, which help students, are steps in the right direction. This attempt to change the present circumstances is essential, particularly when groups do not have equal status. He says that the conditions that keep the 
powerful group in a position of influence have gone on for a long time are complicated and challenging to rectify.

Another sign of change from the political frame is that the university is trying to address low graduation rates. At Missouri S \& T, most students (80\%) choose to major in engineering or science (Missouri University of Science and Technology, n. d.). However, of those students who begin in these fields, not all of them graduate. Some change their major, and others opt to leave the STEM fields and leave college altogether (Chen, 2013). Missouri University of Science and Technology's overall six-year graduation rate for all majors, STEM, and non-STEM is 64\%. While this graduation rate at MS\&T is above the $59.8 \%$ average rate for four-year public institutions (National Center for Education Statistics, 2018), 36\% of all students who attend Missouri University of Science and Technology do not complete their degree, and this is a cause for concern. Consequently, the administration, faculty, and staff at MS\&T have made increasing retention and graduation rates a goal in the university's strategic plan (Missouri S\&T Strategic Plan, 2019). Thus, finding methods to help students finish their degrees is an essential part of reaching that goal, and one could infer that programs such as HGR could be integral to meeting that goal.

It is vital to understand the political landscape because people in power often drive decision-making and policy. According to Bardach and Patashnik (2016), when one studies policies from an analytic perspective, they are viewed logically and with an open mind. However, policy assessment also occurs from an emotional point of view. Individuals do this when they express feelings about an issue which are not necessarily supported by data. Using emotions could explain why policies may be developed and implemented by one group only to find that another group does not see the issue in the same way and rejects it. 
A further political influence that exemplifies how passion and emotion can be instrumental in an organization came from Harvest Collier, Ph.D. As vice provost of academic studies, Dr. Collier was very influential in implementing HGR. His dedication to helping firstyear students make a positive transition from high school to college motivated him to take on the issue of aiding minority students because it was important to him. While these programs were in existence before he became an administrator, he did his best to use both his passion and available data to support these programs, and HGR has continued as a result $(\mathrm{H}$. Collier, personal communication, October 21, 2019). Therefore, it is essential to be aware that facts and data are not the only way to convince a department or college for a proposed change. Policy decisions can be emotionally driven, particularly when personal commitment compels them (Gagliardi, Parnell, \& Carpenter-Hubin, 2018).

To further develop the political frame analysis, Bolman and Deal (2013) discuss the idea that good managers require political skills. An essential part of being a good leader is aware of the context in which they lead. They say having political skills involves knowing how to work with people and understanding how to make decisions when there may be conflicting interests and various opinions within an organization. Bolman and Deal say that how something is presented is as important as what is said. Therefore, with the political frame in mind, changes and new ideas must be given so that they will be understood by those in engineering first. Dr. Collier was a well-respected member of the campus. Even though he was not in the college of engineering, he established a great deal of political influence by his leadership style. One of the ways Harvest Collier did this was that he empowered others. People who worked for him described him as a "wonderful leader, and he made this campus a better place for the students and those who worked with him" (A Gillman, personal communication, December 2019). Even though he was in a high leadership position and in charge of multiple components of the 
university, he still taught classes in his home department of chemistry to maintain a direct connection to his students. Based on all of these characteristics, I think Dr. Collier exhibited servant leadership. According to Northouse (2016), this type of leadership occurs when the leader puts others first and plays to others' strengths, and sincerely wants to help. He elaborates further by saying that a servant leader does not use their position to control other people, but instead makes every effort to distribute decision-making and power to help colleagues reach their full potential.

It is interesting to note when considering HGR from the political frame, this program's mission has changed since its inception. While it began as a way to assist minority and underrepresented students, it has evolved into a program available to all students (R. Morris, personal communication, September 2019). This change occurred approximately seven years ago. At that time, the program was open to any student who could benefit from a summer program and was no longer exclusively for underrepresented students. Not only was it now available to all students, but they added a new emphasis. In particular, HGR became a way for students to improve their math placement scores.

When a student comes to Missouri S \& T to register for their freshman classes, they also must take a math placement exam. The score earned on this test decides which math class is most appropriate for them when they enroll in courses. Various engineering programs widely use math placement tests because math is considered a fundamental component of these degree programs (Heiny, Heiny, \& Raymond, 2017; Ngo, \& Kwon, 2015; Sawyer, 2013). However, to help students, the math department at Missouri University of Science and Technology approached the HGR administration. It proposed that the summer bridge program could be used to improve their score, thus helping them begin their math sequence at a higher level (R. Morris, personal communication, September 2019). 
Consequently, HGR decided that if a student's test scores placed them in either prealgebra or algebra, they could enroll in a math-intensive track. Students attempting to increase their math scores would replace a chemistry unit with an extra math course to make the main concentration to improve their math placement score. Hence, at the end of HGR, the students retake the math placement test, and if their scores improved, they could move up to the next level of math courses for the fall.

A final note on how political influence can work at a university regards these changes to HGR's focus and format. Dr. Collier retired from Missouri University of Science and Technology in 2012. It was after this date that HGR no longer concentrated on minority and underrepresented students. While this does not imply that his leaving caused the change, it is worth mentioning this occurrence. Bolman and Deal (2013) contend that organizations are places where politics exist and have important bearing on policy. Dr. Collier had a personal commitment to helping those in less powerful positions, and when he was no longer leading, the emphasis changed. I do not imply that subsequent leadership has not favored minority and underrepresented students, but that situations of power are complicated (Johnson, 2018), and the solutions to changing them are involved.

\section{Symbolic Frame}

The symbolic frame looks at an organization from an emblematic perspective. A symbol is based on an organization's reputation and identity and stems from its culture. It can be challenging to define what is meant by culture because it often speaks of intangible factors to describe the essence of a group (Schein, 1993/2005). Yet, even though it may be challenging to come up with the correct definition, doing so is an essential part of the group's success. Therefore, it behooves managers to be aware of the culture's impact and do their best to cultivate and encourage one that truly fits with what the company is trying to accomplish. An essential 
part of Missouri S\&T culture is that it is primarily a school for students who study engineering. However, at the same time, another group of students possibly overshadowed if the university only focuses on the engineering side of campus. Hence, leadership needs to find a way to include all students in the culture.

Another vital component of the University of Missouri system's structure is that it is a land grant institution. This designation has various requirements, but the most relevant to my research is that a land grant university must provide accessible education in its community (Brunner, 1966). While the university remains a land grant institute, it is important to note, that in 2018, Missouri S\&T changed its status to highly selective. According to IPEDS (n.d.), 5.9 percent of high school seniors who planned to attend college were able to meet the criteria of being highly selective. This change may not impact providing accessible education, but it is wise to consider at least what this means to the university and potential students. The optics of changing to more selective might be a contradiction between the school's mission and its new designation. Since the administration chose to make this change, this can add insight to what the university considers vital in the way the academic community views them.

While being highly selective is the desired distinction in higher education, Pusser and Marinson (2012) propose that this accolade is somewhat arbitrary because the academy determines this. In doing so, it is the universities that make this category significant. They say that since universities make up their ranking system, they are essentially setting the rules for the standings in which they participate. It serves the current system well, so there is little incentive to revisit the rating system. Consequently, universities determine their influence and the power it allows them to impact decisions. College rankings seem to drive the process, and colleges strive to meet the factors that increase rankings. Thus, the standings continue to support the system as it is. Being highly selective is a coveted distinction, so in some cases, a university may give more 
merit-based aid and do not encourage a diverse application pool or student body. Changing their admission standards could become a part of Missouri University of Science and Technology and supplemental programs like HGR.

Along those same lines, it is significant to consider the change in HGR focus. As noted previously, HGR's initial design helped minority students, but this is no longer the case. Consequently, this effort aimed at students who may need extra assistance no longer exists in its original form. According to Johnson (2018), this is an example of the difficulty of finding a longterm solution when the proposed changes seem short-term in nature. He elaborates further by saying that the problem can have far-reaching effects beyond the individuals and impact entire organizations. While HGR is only one program and its change in the students it targets does not change the university's mindset as the whole, the alteration is symbolic and needs to be considered.

\section{Leadership Analysis}

Leadership and leadership styles are an inherent part of an organization, and leadership has multiple definitions. There are various theories, but no one is best for everyone or every situation (Northouse, 2016). However, one of the primary recurring themes is that effective leaders do not consider themselves static in their roles. Instead, good leaders continually improve what they do through self-reflection (Bryman, 1992; George, 2003; Greenleaf, 1977; Heifetz, 1994; Hersey \& Blanchard, 1969). Therefore, leadership should be a work in progress. Through this process, I need to be mindful of what Levi (2017) said, namely that there are multiple ways to be an effective leader, and there is no "one size fits all."

An additional aspect of governance is the distinction between management and leadership. While both are important in an organization, they serve very different purposes. The manager is more involved in specific daily operations like scheduling and payroll, while the 
leader looks more at the big picture from more of a global perspective (Kotter, 1990). This distinction is intriguing because, frequently, these roles are synonymous. While the same person can be both a manager and a leader, each wields different types of power. According to French and Raven (1959/2012), the manager holds power because they are the official person in charge and have the authority to reward and punish. However, the manager is less likely to possess referent or expert power as these come with a person's vision and not their position. Leaders gain their status because followers admire them, or they have a high level of expertise. Therefore, a title alone cannot make someone a leader. Regarding Dr. Collier, while he was the manager of HGR, he was also a leader. He did have an official leadership role at the university, but his personality and the positive way he treated his colleagues would label him as a leader. Being an ethical leader is also a responsibility for all who are in charge. According to Mihelic, Lipicnik, and Tekavcic (2010), a company cannot be successful without principled leadership. They elaborate further by saying that this ethical behavior can take various forms. Still, the bottom line is that the moral leader must have high personal standards and live according to those ideals. In other words, the leader sets the tone for the company or university and is a role model for all the behaviors. Dr. Collier also exhibited high ethical standards as he guided HGR. When I asked him about his sense of moral leadership, he said he "practiced exhibiting an honest passion for being as effective and committed to leadership roles I've served in, and I've always offered a clear message of transparency and unselfishness in those roles" (H. Collier, personal communication, December 2019). Dr. Collier's reflections were supported by his assistant, who described his leadership as, "Harvest never put himself first, was always honest and was exemplary in his kind and fair treatment of others" (A Gillman, personal communication, December 2019). 
The final component of leadership analysis is aware of the unique nature of leadership in higher education. In most cases, those who serve in administrative roles because they have an advanced degree and have risen through the ranks in an academic department. These leaders may or may not have had formal leadership training and may not feel prepared for their roles in administration (Catalfamo, 2010; Schilling, 2009). Nevertheless, it does not mean this traditional method of choosing leaders cannot be useful. Yet, it reiterates how important it is that a leader must take responsibility for developing their skills. As mentioned previously, good leaders are aware of their shortcomings and are self-reflective (Heifetz \& Laurie, 2011). A leader must be mindful of their behavior and recognize when they are ineffective and require more preparation; thus; an effective leader must be capable of self-awareness and self-reflection.

Dr. Collier has a Ph.D. in inorganic chemistry from Mississippi State University. He became a member of the Missouri S\&T faculty in 1982 as an assistant professor of chemistry. Dr. Collier became an associate professor in 1988 and professor in 1994. From 1996-1999, he served as chair of the chemistry department, and from 1999-2002, he was associate dean for the College of Arts and Sciences. He became vice provost for undergraduate and graduate studies in 2001, and in 2007 he became vice provost for undergraduate studies. Hence, Dr. Collier came to a leadership position through the traditional route, but as Catalfamo (2010) and Schilling (2009) point out, he thrived by engaging in leadership development activities. His desire to develop his skills is evident in his description of leadership in higher education. He said, "As you may imagine, describing a leadership philosophy in the context of a higher education academic environment is challenging because of the significant variety of situations that exist. This range of situations includes students, faculty, and staff interactions. From my perspective, communicating an effective "lead by doing" or indeed a demonstrated willingness to participate in pursuing desired outcomes is perhaps the most crucial factor to integrate into the leadership 
role" ((H. Collier, personal communication, December 2019). Thus, Dr. Collier demonstrated a desire to learn and be impactful as a leader even though his formal training was in chemistry.

\section{Implications for Research in the Practitioner Setting}

Missouri University of Science and Technology is committed to student retention and improving graduation rates and has stated this as one of its goals in the strategic plan (Missouri S\&T Strategic Plan, 2019). Therefore, the results of this research can provide information to help the university address this goal. Data-driven decisions are critical in understanding what it takes for students to be successful and graduate. I hope that this and other research can help the university find the best resources to make that possible.

\section{Summary}

In summary, this section provided an overview of Missouri University of Science and Technology and HGR. It delved into the history of both and also provided an organizational and leadership analysis. This historical perspective showed the changes that have occurred and how HGR has come to be what it is today. The purpose of knowing the history of an organization is to understand its function or propose change (Brunninge, 2009). In this case, I plan to suggest changes, so I need to learn about the university and its programs. Effective changes can involve small modifications or even revitalizing an old concept (Bolman \& Gallos, 2011). Therefore, I need to know their history so I can recommend changes that will work.

This section on practitioner setting also provided an organizational analysis using the method proposed by Bolman and Deal (2013). It included examining Missouri University of Science and Technology and HGR from the structural, human resource, political and symbolic frames. Just like the importance of knowing the history of the organization, understanding the multi-dimensional aspects of an organization helps make suggestions that may come about as the result of my study (Jansson, 2013). Finally, I provided a leadership analysis for Harvest Collier, 
Ph.D., who was instrumental in developing HGR to what it is today. Because of his active involvement in the program, understanding his leadership was helpful in the overall analysis. 


\section{SECTION III: SCHOLARLY REVIEW FOR THE STUDY INTRODUCTION}

When someone decides to attend college, they have many choices for their major.

According to one resource, there appear to be over 1,800 majors a student can pursue in college (MyMajors.com, 2019). One specific group in that collection are science, technology, engineering, and mathematics. These disciplines are collectively and commonly referred to as STEM, which stands for education in science, technology, engineering, and mathematics. The number of students who pursue these majors is on the rise (National Science Board, 2018). The term STEM was first presented by the U.S. National Science Foundation (NSF) in 2001. These disciplines and topics of study existed before that time. However, after these majors got this collective label, the interest and awareness of STEM-focused education came to the forefront.

Since it received a specific label, STEM has continued to be a popular choice among college students (National Science Board, 2018). Perhaps this is also because STEM is even more significant now as the world is increasingly more connected. Every day people use and rely on computers or smartphones both at work and in their personal life. Technology is pervasive in the workplace as well as instrumental to personal communication (Goldstein, \& Katz, 2008). Science is also becoming more important as the disciplines of medicine, biology, and chemistry are continually making new contributions to the way humans live in cancer research and investigating solutions to environmental concerns (Rull, 2014).

Consequently, there has been an increase in students who start college intending to earn a degree in STEM. However, approximately half of these students graduate with a degree in that major (National Academics of Science, Engineering, and Medicine, 2016). The remaining STEM students either change their major or leave college altogether (Chen, 2013). However, it is important to note that this problem has existed for many years as various researchers have found 
little change in this graduation rate in the past 60 years of study (Besterfield-Sacre, Altman, \& Shuman, 1997; Geisinger, \& Raman, 2010).

Low graduation rates are of concern for all college students, but can be of particular concern for students who major in science, technology, engineering, and mathematics (STEM) because the workplace is changing. As STEM skills become more critical, the lower degree completion can have far-reaching effects on a persons' employability. Without a STEM degree, person's competitive edge can be diminished (National Science Board, 2018). Not having a STEM degree can put students at a deficit because they do not have the required skill set necessary for employment in the current job market (Rothwell, 2013; Vedder, 2018). Additionally, if students complete college with a non-STEM major, they may be less employable or earn less money. According to Kokkelenberg, and Sinha (2010) and Russell, and Atwater (2005) graduates from STEM fields attain higher career earnings and social status positions than many other areas.

Not completing a degree is problematic for colleges and universities as well. Colleges lose tuition dollars from students who leave before graduation, and low degree completion rates discourage potential students because they do not want to attend a school where few students graduate (Schneider \& Yin, 2011). As a result, colleges also want students to graduate.

Therefore, due to the concern over sustained low graduation rates in STEM and all fields, universities have explored various ways to help students be successful and graduate from college (Jones \& Braxton, 2010). They want to be sure they are providing students with the appropriate resources to complete their degrees. While institutions of higher education want to address the low graduation rates in all fields, look specifically at STEM majors. This concern comes amid the worry that the United States may have difficulty being a competitive force in the global economy with such low graduation rates in STEM. (National Academies of Science, Engineering 
and, 2016). Hence, universities see a need to find ways to help their students be successful and complete their college degrees.

This dissertation-in-practice aimed to examine one of the strategies that universities have used to increase student retention. I specifically studied Hit the Ground Running (HGR), a summer bridge program at Missouri University of Science and Technology. I gave a critical overview of what was involved in this program and outlined what students said regarding how it helped them. This analysis provides information for all students, but I paid particular attention to those tactics that targeted students pursuing STEM-focused degrees. This research also presented theoretical frameworks for studying how colleges can work to retain students in higher education.

\section{Summer Bridge Programs}

Universities employ numerous strategies to help their students remain in school and be successful. One approach some colleges use is to offer preliminary, supplemental programs. Traditionally, these programs occur before school starts and help prepare students for college. The first recorded summer bridge program was in 1980 at the University of North Carolina, Chapel Hill. This program was a way to help first-year students adjust to the social and academic demands of college. It is open to all students and is still offered to incoming first-year students and plans to commemorate 40 years in existence during 2020. (University of North Caroline at Chapel Hill, n.d.).

Since these supplemental classes often occur in the summer before college starts, they are commonly referred to as a summer bridge program (Ashley, Cooper, Cala \& Brownell, 2017; Relles \& Tierney, 2014). The specific content of these preliminary programs varies across universities, but most of them include three parts. The first is an orientation or introduction to college classes. The second component is that students have interactive involvement with 
academic advisors and take rigorous college courses along with the support they need to be successful in these courses. The final element is that these students live on campus; thus, these programs also introduce the social aspect of college. (National Center for Education Statistics, 2016).

Summer programs differ regarding the students they target. Many are for specific populations, such as unprepared or “at-risk” students (Cairncross, Jones, Naegele, \& VanDeGrift, 2015; Doerr, Ørlebìck, \& Costello, 2014; Reisel, Jablonski, Hosseini \& Munson, 2012). Other focus on underrepresented students (Bruno, Wren, Noa, Wood-Charlson, Ayau, Soon \& Chy, 2016; Gilmer, 2007; Sablan, 2014), and some are open to all incoming freshmen (Harkins, 2016; Wheeler \& Wischusen, 2011). Summer bridge programs also vary in the subject area. The vast majority of programs are specifically for STEM and engineering students (Ashley, Cooper, Cala, \& Brownell, 2017). Still, others concentrated on writing skills (Buck, 1985; Kallison \& Stader, 2012; McCurrie 2009; Wathington, Pretlow, \& Barnett, 2009) or college preparation in general (Wolf-Wendel, Tuttle, \& Keller-Wolfe, 1999). An additional factor to consider in the study of summer programs is the goal of these programs. These goals are complex but seem to fall into three broad categories: academic success goals, psychosocial program goals, and department-level goals (Ashley, Cooper, Cala, \& Brownell, 2017).

While many colleges offer summer programs, reports on their effectiveness are often not available. Compared to the number of programs available, there is very little published scholarly information (Ashley, Cooper, Cala, \& Brownell, 2017; Sablan, 2014). Additionally, published material varies considerably in terms of research questions investigated and methodologies utilized. Therefore, since there is limited information in published journals, this literature review will present findings from published and unpublished reports of various summer programs. 


\section{Summer Bridge for Unprepared/“At Risk” Students}

At some colleges, summer bridge programs are required or recommended for students considered "at-risk" by their university (Douglas \& Attewell, 2014). Finding a specific definition for these vulnerable students is challenging and multifaceted (Abbott, n.d.). For this literature review, this distinction will refer to students who, due to various circumstances, have a high probability of having difficulty being successful in school.

Many programs target students who did not meet the standard admission criteria at a specific university, so they are considered at-risk. In many of these reports, to measure effectiveness, participants are often compared these students to a similar group on campus. Various researchers found participants more likely to return for their sophomore more year at a higher rate due to their participation (Buck, 1985; Cabrera, Miner, \& Milem, 2013; Garcia, 1991; Gold, 1992). However, not all bridge programs for at-risk students resulted in higher retention rates (Wathington, Pretlow, \&Barnett, 2009). This particular summer bridge program did not show an increase in students returning after first-year students year. The reason cited for this result may not be that the program was not effective. Instead, the control group to which they compared the summer bridge program students enrolled in a different but similar enrichment program. Therefore, the program they investigated may have impacted students but was not statistically significant in their experimental design.

Other investigations looked at the impact summer programs had on the subsequent college grade point average (GPA) of at-risk students. A program for conditionally admitted students found almost all (98\%) participants successfully passed the summer courses and started that fall at the university (Nemelka, Askeroth, \& Harbor, 2018). These students also achieved better than expected GPA's during their first semester. Bir and Myrick (2015) also found students who took supplemental courses before school passed their first-year classes at a higher rate than 
non-participants. Likewise, Wheatland (2002) and Strayhorn (2011) found that at-risk students got better grades than non-participants after taking summer coursework. Moreover, additional studies found that students who participated in a supplemental before college were more likely to pass their classes and had higher GPAs compared to non-participants, and this increase existed through all four years of the study (Graham, et.al. 2013; Quiroz \& Garza, 2018). However, not all summer bridge programs resulted in higher GPA's for participants. Various researchers did not report any significant differences between participants' grades compared to non-participants (Ackerman, 1991; Evans, 1999; \& Wolf-Wenedle, Tuttle \& Keller- Walpole, Simmerman, Mack, Mills, Scales, \& Albano, 2008; Wolf, 1999).

\section{Summer Programs for STEM and Engineering Students}

Another group of studies investigated summer programs designed specifically for those students in STEM majors and some particularly for those in engineering. This portion of the literature review will align with my dissertation's purpose and discuss various bridge programs based on their stated objective. There are multiple objectives targeted in summer bridge programs for engineering students. The ones presented are related to my research questions. The specific goals that will be covered are: whether or not there was an observed increase in GPA, an increase in math placement scores, an increase in graduation rates, and finally, whether or not there was an increase in self-efficacy for students. It is important to note that some researchers explored more than one goal. Therefore, some results are in more than one goal section.

\section{Grade Point Average (GPA)}

Various studies found higher GPA's for students after they participated in summer bridge programs for STEM and engineering compared to those who did not participate (Doerr, Ørlebìck, \& Costello, 2014; Gilmer, 2007; Maton, \& Beason, Godsay, Domingo, Bailey, Sun, 
\& Hrabowski, 2016; Pritchard et al., 2014; Raines, 2012; Wheeler \& Wischusen, 2014; Windsor, Russomanno, Bargagliotti, Best, Franceschetti, Haddock, \& Ivey, 2015). Conference proceedings also gave evidence for increased GPA (Cairncross, Jones, Naegele, \& VanDeGrift, 2015; Citty \&Lindner, 2012; Harkins, 2016; Persaud \& Freeman, 2005; Wheatland, 2002). Even though these were not from published reports, I included them in the knowledge base due to the small number of published works on this topic (Creswell, 2014).

Not all summer bridge programs found that participation resulted in higher GPAs. In the only available published research, the investigators proposed this was due to different circumstances of the math placement testing (Gleason, Boykin, Johnson, et al., 2010). When students come to this university to study engineering, they take a math placement test. Because the students in the bridge program took their test after an intensive math preparation, it is possible, their score on the test was not indicative of their actual ability. Therefore, comparing participants to non-participants was not equivalent, but placement resulted from different conditions. Hence, this difference may be what influenced the student's performance and not the summer bridge program.

Additionally, other researchers did not report that students had higher GPAs after participating in bridge programs (Tomasko \& Ridgway et al., 2016). Upon further investigation, they attributed this to external factors. They speculated it was due to teacher quality. They reported that summer bridge teaching was of a higher caliber than during the semester, contributing to the lower grades. Another conference proceeding that did not find higher grades did not attribute the finding to low teacher quality but instead felt it was due to adjustment issues. They made this conclusion because they found students had higher grades in subsequent semesters, so they thought it was because more time in college allowed them to be more familiar 
with the environment at a university (Nite et al., 2015). Consequently, as researchers report differing results regarding grades, it is necessary to investigate this aspect further.

\section{Math Placement}

Another focus of a summer bridge program is to improve math placement scores at some schools that offer STEM majors. The initial math course in which students enroll is significant for their degree progression. The math class in which students begin their study is foundational for subsequent coursework for STEM majors (Hilgoe, Brinkley, Hattingh, \& Bernhardt, 2016). Therefore, if a summer bridge program can positively change a student's math placement, it can increase overall retention at the university. Most studies that focused on math placement in summer programs found students showed an overall increase in their score (Ami, 2001; Doerr, Ørlebìck, \& Costello, 2014; Raines, 2012; Reisel, Jablonski, Hosseini \& Munson, 2012).

Additionally, reports from conference proceedings also described the same outcome (Bochis et al., 2007; Diefes-Dux, 2002; Fletcher, Newell, Newton, \&Anderson-Rowland, 2001; Kowalchuk, Green, Ricks, \& Nicklow, 2010; Varde, 2004). Even though these reports are not in published research, they support providing additional anecdotal evidence to illustrate the impact of summer bridge programs. The increased placement score resulted in the student enrolling in a higher-level math class than would have been possible without the intervening program. Thus, using this metric, summer bridge programs impact students with the potential to effect retention and graduation rates. It is important to note that none reported a decrease in math placement scores after participation in a bridge program of the research consulted.

\section{Graduation Rates}

Yet another goal of summer bridge programs is to increase graduation rates for STEM and engineering majors. Several researchers reported a higher percentage of engineering students who participated in a summer program graduated from college compared to those who did not 
(Gilmer, 2007; King \& Masterson, 201; Murphy, Gaughan, Hume, \& Moore, 2010; Riesel, Jablonski, Hosseini, \& Munson, 2012). Once again, conference proceedings also supported the results and reported that students were more likely to graduate than non-participants (Kopec, \& Blair, 2014; Maton, Beason, Godsay, Domingo, Bailey, Sun, \& Hrabowski, 2016; Persaud \& Freeman, 2005). While there are not many published studies that report an increase in graduation rates after participating in a summer bridge, none of the research or results presented at conference proceedings reported a decrease in graduation rates after participating in a summer program.

\section{Self-Efficacy}

Various researchers reported an increase in student self-efficacy as a result of the precollege coursework (Bruno, Wren, Noa, Wood-Charlson, Ayau, Soon \& Chy, 2016; Maton, Beason, Godsay, Domingo, Bailey, Sun, \& Hrabowski, 2016; Russomanno, Best, Ivey, Haddock, Franceschetti, Hairston, Dydlodeoh, 2010; Strayhorn, 2011; Wheeler \& Wischusen, 2014; Windsor, Russomanno, Bargagliotti, Best, Franceschetti, Haddock, \& Ivey, 2015). Also, Cairncross, Jones, Naegele, and VanDeGrift (2015) also presented findings at a conference that showed students reported an increase in their sense of confidence in their ability to be successful after participating in a summer bridge program at the University of Portland.

Another research project looked at the specific cognitive effects of a summer bridge program. Murray, Dukes, and Weidner (2018) found that students who participated in a precollege STEM program showed increased grit scores. Grit is defined by Duckworth \& Quinn (2007) as a student's persistence in college and an individual's commitment to their academics by putting forth the effort needed to succeed in school. Furthermore, these high grit scores were the direct result of participating in a summer program (Murray, Dukes, \& Weidner, 2018). Grit is an influential element in college success because it links to self-efficacy. When both grit and 
selfefficacy are present, there is a commensurate increase in college success, as evidenced by an increase in GPA (Alhadabi \& Karpinski, 2019). Therefore, if a bridge program influences grit or self-efficacy, this may be a critical factor in college success and, in particular, for those students pursuing STEM majors.

Other studies did not find an improvement in student self-efficacy after they participated in a summer bridge program. Raines (2015) found that students reported a decrease in their confidence in their ability after the summer program. The students were asked to record their confidence in their math ability before the summer program and then after their first semester of course work. Student participants showed a marked decrease in the sureness of their math ability, although this research did not include a control group with which to compare self-efficacy scores. Perhaps all students showed a drop in their confidence as they began course work, but the only students measured were those in the summer bridge program.

In a mixed-methods approach, Wolf-Wendel, Tuttle, and Keller-Wolfe (1999) did not find an increase in self-efficacy after students participated in a summer bridge program. The reason for this finding may be that the summer bridge program was open to all students, including those of high and low ability. When the researchers looked only at students with lower academic ability, participants did show higher self-efficacy scores on their quantitative measure as well in their focus group analysis. Therefore, it may not be that the program does not help students increase their sense of confidence in themselves. Instead, it would be more evident if the students' groups were analyzed after taking into account their academic ability. While WolfWendel, Tuttle, and Keller-Wolfe did not focus exclusively on STEM or engineering majors, their research adds to the overall discussion of students, self-efficacy, and college success. 
Another essential factor to consider is that the reason students do not persist in STEM and engineering degrees is multifaceted (Geisinger \& Raman, 2010). There are various reasons contributing to whether or not a student completes their degree. However, these researchers propose that students who do not persist in STEM or engineering programs are often interrelated, and a common theme seems to be that ultimately they do not feel confident in their abilities. Hence, investigating self-efficacy as it relates to degree completion is an important variable to explore.

\section{Summary}

In summary, STEM education is becoming increasingly important in the job market (National Science Board, 2018). At the same time, universities are reporting concerns that graduation rates in STEM are decreasing. These two issues are related and require attention. As a result, universities are seeking ways to increase retention and student success, and there are various proposed solutions. However, to choose the best methods, data must inform decisions regarding plans to help students graduate from college once they start (Datnow \& Park, 2014).

This literature review gives evidence to information that can help universities make informed decisions about retention. Specifically, it looked at the impact of summer bridge programs. The results show mixed outcomes regarding the influence of such programs; therefore, further and a specific investigation is required. In particular, the available research indicates that a summer bridge program has benefits but should be investigated explicitly at each university where they exist. Hence, the summer program at Missouri University of Science and Technology, Hit the Ground Running (HGR), should be examined to see what type of effect it has on its students. 


\section{SECTION IV: CONTRIBUTION TO PRACTICE}

Section four of my dissertation in practice provides a power point presentation on the results and conclusions from my study. Since I focused on the impact of the summer bridge program, Hit the Ground Running, I intend to present this to the individuals who oversee this program. Namely, those would be the Vice Provost for Academic Affairs at Missouri University of Science and Technology as well as the Assistant Vice Provost for Student Services. The reason for including the Assistant Vice Provost is because the person in this position is the one who oversees Hit the Ground Running and its day to day operations. I will arrange a time to present my conclusions when my committee has approved it. I want to present this in person so I can elaborate on my findings and answer any questions or concerns that they may have after reading the results. The presentation slides are provided below.

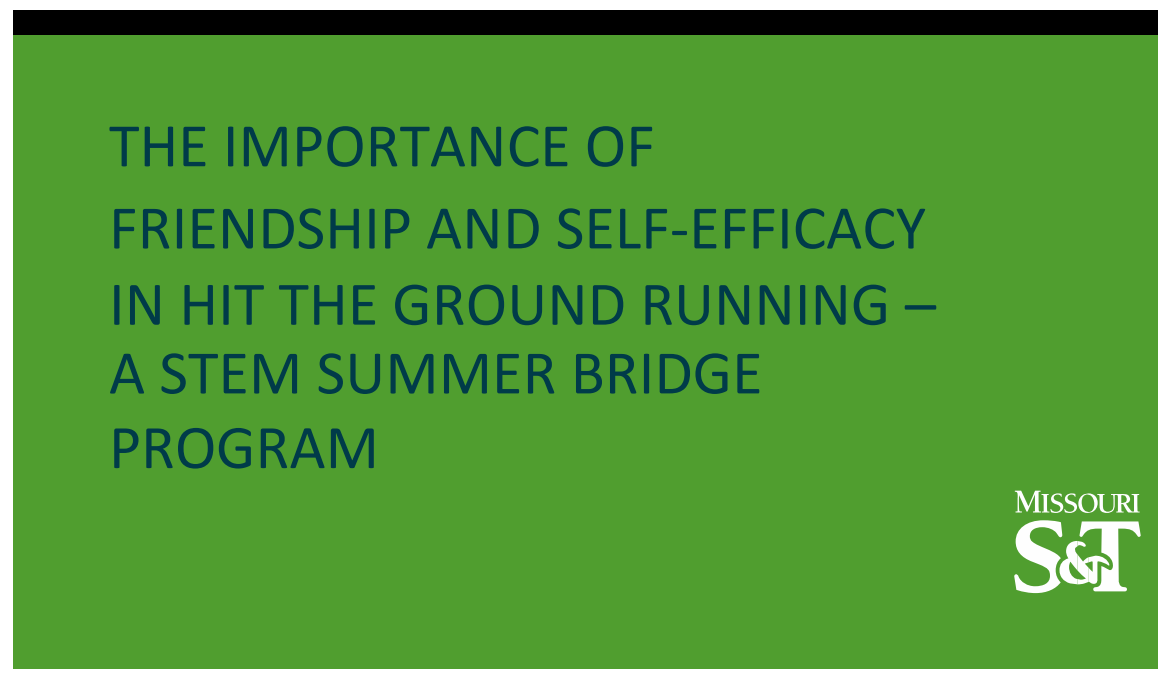


Hit the Ground Running

> History of HGR - Realistic college experience, both academically and socially to increase success

Hit the Ground Running

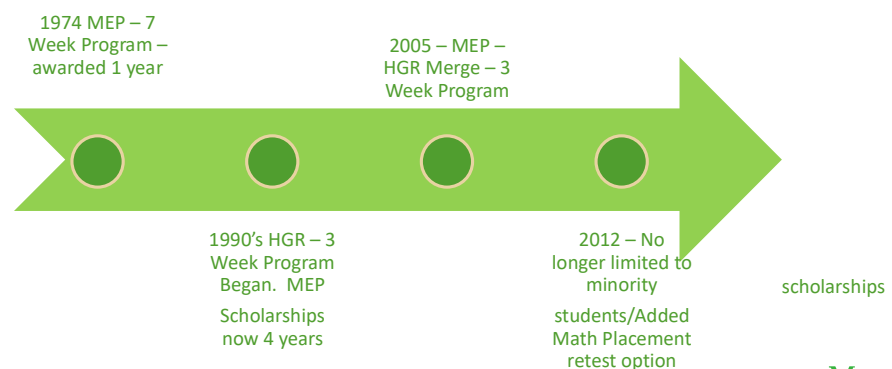

MISSOURI

S\&T

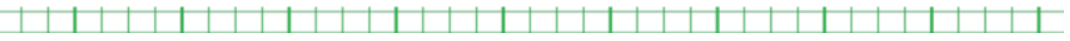

Hit the Ground Running

$>$ Research Question

> Convergent Mixed Method Design

- Quantitative: Cohorts from 2014 - 2019, 448 students

\begin{tabular}{l|c|c|c|c|c|c|}
\hline $\begin{array}{l}\text { Year of } \\
\text { Enrollment }\end{array}$ & 2014 & 2015 & 2016 & 2017 & 2018 & 2019 \\
\hline $\begin{array}{l}\text { Number of } \\
\text { students }\end{array}$ & 60 & 91 & 81 & 75 & 76 & 88 \\
\hline
\end{tabular}
$\begin{aligned} & \text { Qualitative: semi-structured interviews with past } \\
& \text { participants }\end{aligned}$
\begin{tabular}{l} 
MisSOURI \\
\hline
\end{tabular}

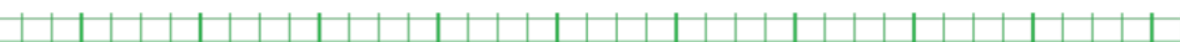

Description of participants

$>$ Math Placement Scores - 2 Tests 
> Missouri Math Placement Test (MMPT) - 40-question, multiple choice algebra placement test

$>$ Trigonometry placement test - 25-question multiple choice exam

$>\mathrm{ACT}$

$>$ High School GPA

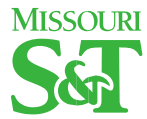

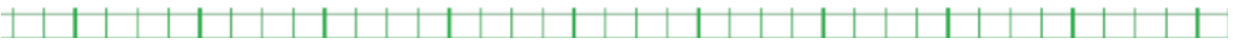 Results}

$>$ Descriptive statistics only - No comparison group

\begin{tabular}{|c|c|}
\hline Average ACT Score & $\mathbf{2 7 . 3 1}$ \\
\hline Average GPA & 3.62 \\
\hline
\end{tabular}

MISSOURI

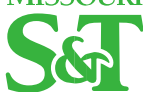

\begin{tabular}{|c|c|c|c|}
\hline Cohort & HGR & MS\&T & Results \\
\hline $\begin{array}{c}2014 \\
6 \text { year graduation rate }\end{array}$ & $68 \%$ & $66 \%$ & \\
\hline $\begin{array}{l}2015 \\
5 \text { year graduation rate }\end{array}$ & $57 \%$ & $53 \%$ & \\
\hline $\begin{array}{l}2019 \text { First Year } \\
\text { Retention }\end{array}$ & $88 \%$ & $81 \%$ & MISSOURI \\
\hline
\end{tabular}

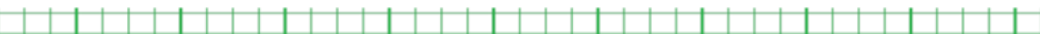

Results

$>$ Paired sample t-test found significant difference in math placement scores after participating in HGR

$>$ Note - not all retook placement tests. Reasons:

- Their score was satisfactory

- Math was not needed for their major 


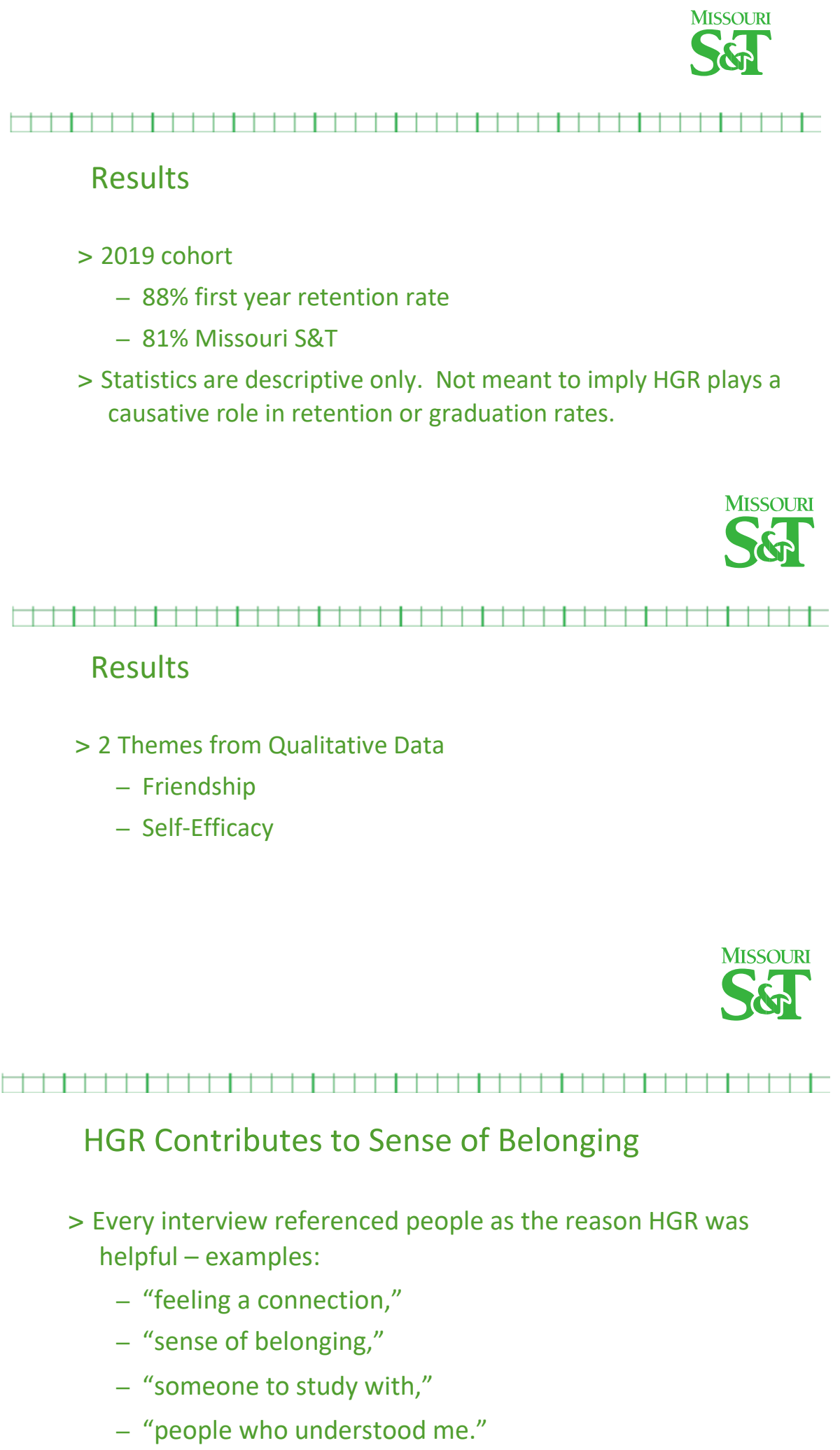



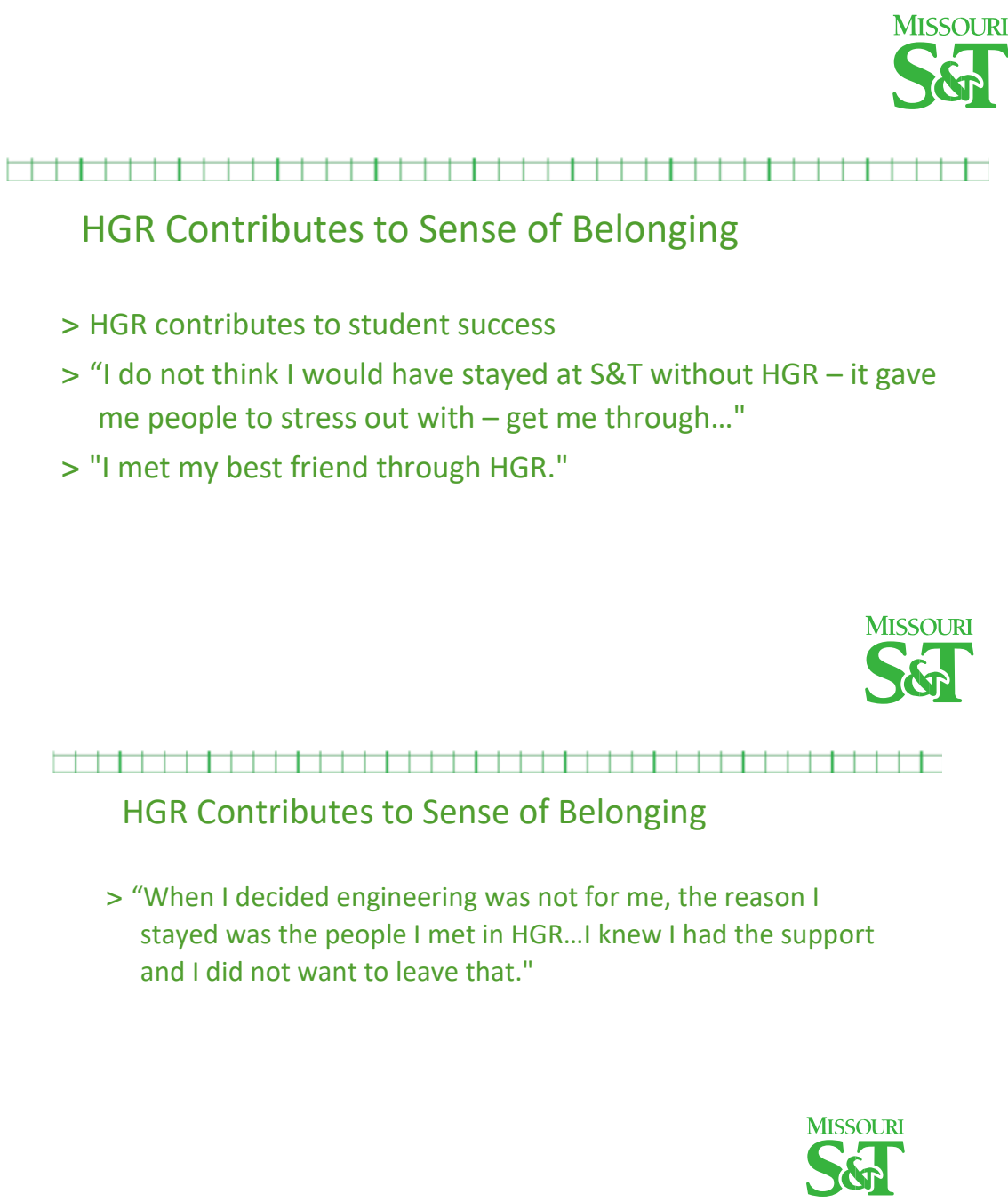

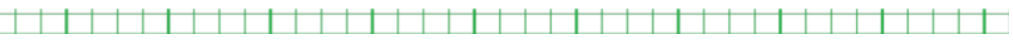

\section{HGR Contributes to Self-Efficacy}

> "HGR gave me a bridge between high school and college since I did not have to study in high school, it let me see what college was going to be like."

$>$ "It helped me feel ready once the craziness (of the semester) begins."

$>$ "I learned the expectations of S\&T - you can't get by doing the bare minimum." 
$>$ Interesting finding - even though most students cited a chance to improve their math placement scores for their reason to enroll in HGR, they did not attribute this to their success

\section{nisuren

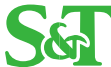

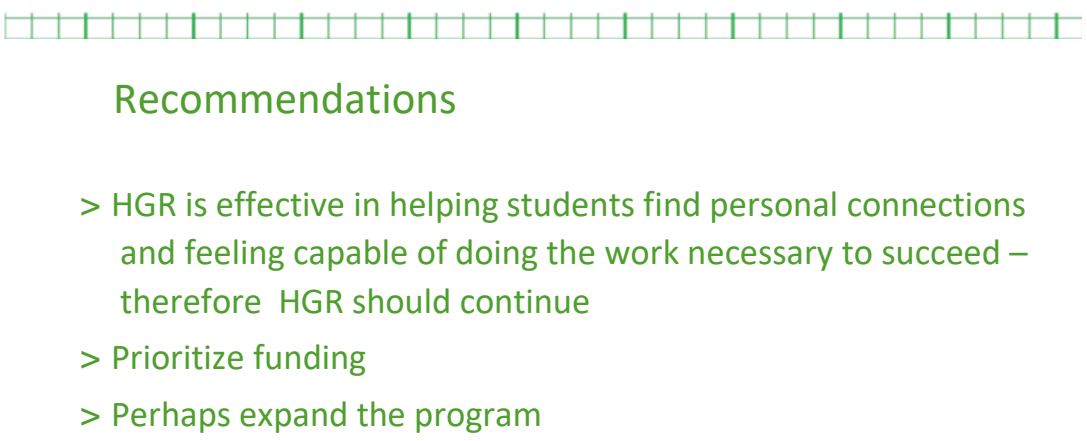

$>$ HGR is effective in helping students find personal connections and feeling capable of doing the work necessary to succeed therefore HGR should continue

$>$ Prioritize funding

$>$ Perhaps expand the program
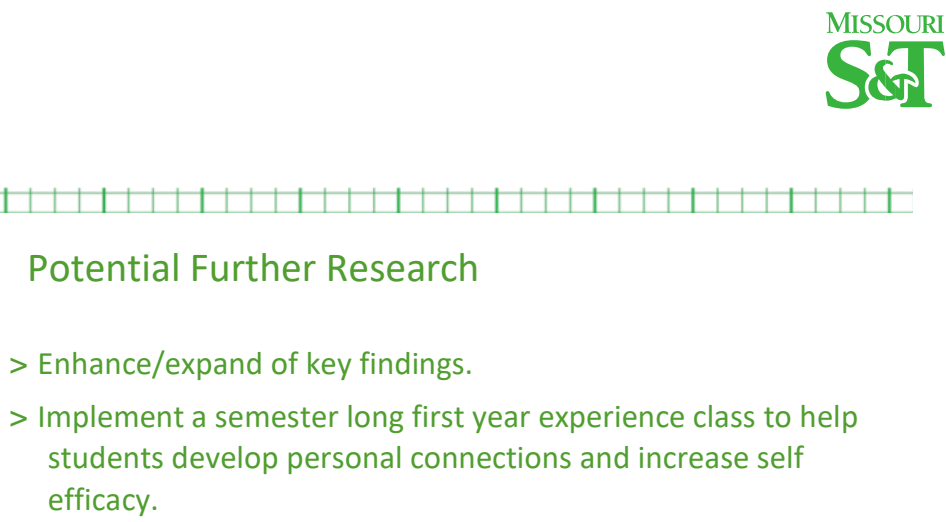


\section{SECTION V: CONTRIBUTION TO SCHOLARSHIP}

Section five of my dissertation in practice is my plan for my research to contribute to scholarship. One way to do this is by submitting my findings to a journal for publication. The journal to which I plan to submit my dissertation is the Journal of College Student Retention: Research, Theory and Practice. The reason I chose this journal is that through my literature review, many research articles came from this publication. It is targeted at information that relates to student retention and attrition in higher education. Since Hit the Ground Running is intended to help students remain at Missouri University of Science and Technology and graduate, this journal would be appropriate.

Another reason for choosing the Journal of College Student Retention: Research, Theory and Practice is in its description it states that it wants to feature and distribute information to colleges. They are committed to making institutions of higher learning aware of programs that can help students stay in college. The goal of my dissertation is to contribute to the knowledge base, so this journal is the best place to make sure that occurs.

In order to submit my dissertation in practice to this journal, I will need to establish an account. Once I have created an account, I will submit my manuscript online. The address to which I will upload my paper is http://mc.manuscriptcentral.com/jcsr. When I submit my dissertation, I must limit myself to two files. One of them is a cover page with my personal information, such as my name and contact information. The other submission is the actual manuscript, and the first part of it will be the abstract. The document cannot contain any personal information. Therefore, I will need to make sure I remove any identifying data from the paper I submit. The journal provides detailed directions on how to remove identifying information from the properties area of the document. The reason for this is because all manuscripts are reviewed anonymously. 
The Journal of College Student Retention: Research, Theory and Practice requires all submissions must follow the APA 7th edition. I must also submit an abstract which cannot exceed 150 words. My work must also be original. Before submission, the journal recommends obtaining a copy of previous editions. The rationale for this is to help make me aware of the style of writing they expect. Therefore, I may need to edit some portions of my dissertation in practice to make it suitable to the design of the journal.

THE IMPORTANCE OF FRIENDSHIP AND SELF-EFFICACY IN A PRECOLLEGE STEM SUMMER BRIDGE PROGRAM

Earning a college degree can have multiple benefits, including increased earnings (Doubleday, 2013), living longer (Hummer \& Hernandez, 2013), and higher-level reasoning and cognitive skills (Pascarella \& Terenzini, 1991). However, not everyone who begins college graduates. According to the National Center for Education Statistics (2018), only 59\% of students enrolled in college at a public institution earn their degree within six years. Low graduation rates are of concern for all college students but can be of particular concern for students who major in science, technology, engineering, and mathematics (STEM) because the workplace is changing. As STEM skills become more critical, the lower degree completion can have far-reaching effects on a persons' employability. Without a STEM degree, a person's competitive edge can be diminished (National Science Board, 2018). Students can be at a deficit because they do not have the required skill set necessary for employment in the current job market (Rothwell, 2013; Vedder, 2018). Furthermore, if students complete college with a nonSTEM major, they may earn less money or have reduced social status (Kokkelenberg \& Sinha, 2010; Russell \& Atwater, 2005).

There has been an increase in the number of students who begin college with the intent of majoring in STEM; however, approximately half of these students graduate with a degree in their 
original major (National Academies of Science, Engineering, and Medicine, 2016). Some of these students change their majors, others leave the STEM fields and some drop out of college (Chen, 2013). It is important to be aware that low completion rate has remained unchanged over the past 60 years (Besterfield-Sacre, Altman, \& Shuman, 1997; Geisinger, \& Raman, 2010).

Low graduation rates are problematic for colleges and universities as well. Colleges lose tuition dollars from students who leave before graduation, and low degree completion rates discourage potential students. According to Schneider and Yin (2011), students do not want to attend a school where few students graduate. As a result, colleges are directing their efforts to increase retention and graduation rates for their students (Jones \& Braxton, 2010; Vedder, 2018).

\section{Summer Bridge Programs}

To increase student success, one approach some colleges use is to offer supplemental programs. Traditionally, these pre-college programs that help prepare students for college and are referred to as a summer bridge program (Ashley, Cooper, Cala \& Brownell, 2017; Relles \& Tierney, 2014). The first recorded summer bridge program was in 1980 at the University of North Carolina, Chapel Hill. This program was designed to help first-year students adjust to the social and academic demands of college. It was open to all students and is still offered to incoming first-year students and the program will commemorate 40 years in existence in 2020 (University of North Carolina at Chapel Hill, n.d.).

The specific content of these summer bridge programs varies across universities, but most of them include three parts. The first is an orientation or introduction to college classes. The second component is that students have interactive involvement with academic advisors and take rigorous college courses and the support they need to be successful in these courses. The final element is that these students live on campus, thus introducing the social aspect of college (National Center for Education Sciences, 2016). 
Summer programs also differ regarding the students they target, but many programs are specifically for STEM and engineering students (Ashley, Cooper, Cala, \& Brownell, 2017). It is also important to note that even though many colleges offer various summer programs, reports on their effectiveness are often unavailable. Compared to the number of programs in use, there is little published scholarly information (Ashley, Cooper, Cala, \& Brownell, 2017; Sablan, 2014). Additionally, published material varies considerably in terms of research questions investigated and methodologies utilized.

\section{Summer Programs for STEM and Engineering Students}

Since STEM education is becoming more critical in the job market (Rothwell, 2013), some universities offer summer programs designed specifically for those students majoring in STEM, particularly engineering. Bridge programs for engineering students concentrate on a variety of benefits and outcomes; the following sections summarize the literature according to key program objectives.

\section{Math Placement}

For engineering students, the initial math course in which students enroll is significant for their degree progression. Math placement is important because it is foundational (Hilgoe, Brinkley, Hattingh, \& Bernhardt, 2016). Therefore, if a summer bridge program can positively change a student's math placement, it could increase overall retention at the university. Most studies that focused on math placement in summer programs found students showed an overall increase in their score (Ami, 2001; Doerr, Ørlebìck, \& Costello, 2014; Raines, 2012; Reisel, Jablonski, Hosseini \& Munson, 2012). Reports from conference proceedings also described the same outcome (Bochis, Hsia, Johnson, Boykin, Wood, Bowen, \& Whitaker, 2007; Diefes-Dux, 2002; Fletcher, Newell, Newton, \&Anderson-Rowland, 2001; Kowalchuk, Green, Ricks, \& Nicklow, 2010; Varde, 2004). The increased placement score resulted in the student enrolling in 
a higher-level math class than would have been possible without the intervening program. Thus, using this metric, summer bridge programs impact students with the potential to influence retention and graduation rates. It is also noteworthy that none of the studies reported a decrease in math placement scores after participation in a bridge program.

\section{Graduation Rates}

Various summer bridge programs reported increased graduation rates for STEM and engineering majors. The participants in these programs had higher graduation rates than those who did not participate (Gilmer, 2007; King, \& Masterson, 2011; Murphy, Gaughan, Hume, \& Moore, 2010; Riesel, Jablonski, Hosseini, \& Munson, 2012; Tomasko, Ridgway, Waller, \& Olesik, 2016; Windsor et al., 2015). Conference proceedings also supported the results and said students were more likely to graduate than non-participants (Kopec, \& Blair, 2014; Maton et al., 2016; Persaud \& Freeman, 2005).

\section{Self-Efficacy}

Self-efficacy is the extent to which someone has confidence in their ability to accomplish a task and it something that impacts their capacity to do the actions (Bandura, 1997). Some colleges offer summer programs that focus on increasing self-efficacy. They base this on the idea that students with confidence in their abilities are much more likely to attempt and persist academically. In contrast, people with low self-efficacy may avoid even starting in the first place (Bandura \& Jourdan, 1991). Hence, participating in a pre-college program has the potential to impact self-efficacy.

Some of students' increase in self-efficacy was attributed to pre-college coursework (Russomanno et al., 2010; Strayhorn, 2011; Wheeler \& Wischusen, 2014). The University of Portland found an increase in students' sense of confidence in their ability to be successful after participating in a summer bridge program (Cairncross et al., 2015). Another study of the specific 
cognitive effects of a summer bridge program found a positive correlation between students who participated in a pre-college STEM program and their grit score (Murray, Dukes, \& Weidner, 2018). Grit is defined by Duckworth \& Quinn (2007) as a student's persistence in college and an individual's commitment to their academics by putting forth the effort needed to succeed in school. Grit is an influential element in college success because it is linked to self-efficacy, so when both grit and self-efficacy are present, there is a commensurate increase in college success, as evidenced by an increase in GPA (Alhadabi \& Karpinski, 2019). Therefore, if a bridge program influences grit or self-efficacy, this may be a critical factor in college success and, in particular, for those students pursuing STEM majors.

However, other studies did not see students' improved self-efficacy after they participated in a summer bridge program. Raines (2015) found that students reported a decrease in their confidence in their ability after the summer program. The students were asked to report their confidence in their math ability before the summer program and then after their first semester of course work. Student participants showed a marked decrease in the sureness of their math ability, although this research did not include a control group to compare self-efficacy scores. Perhaps all students showed a drop in their confidence as they began course work, but the only students measured were those in the summer bridge program.

Wolf-Wendel, Tuttle, and Keller-Wolfe (1999) similarly did not find an increase in selfefficacy after students participated in a summer bridge program. However, the reason for this finding may be that the summer bridge program was open to all students, including those of high and low ability. When the researchers looked only at students with less academic knowledge, participating did show higher self-efficacy scores on their quantitative measure as well in their focus group analysis. Therefore, it may not be that the program does not help all students increase their sense of self-confidence, but may be most impactful for those with less academic 
preparation. While Wolf-Wendel, Tuttle, and Keller-Wolfe did not focus exclusively on STEM or engineering majors, their research adds to the overall discussion of students, self-efficacy, and college success.

\section{History of Hit the Ground Running}

Since each bridge program is specific to each university's needs, this study examined the summer bridge program at Missouri University of Science and Technology known as Hit the Ground Running (HGR). It is a three-week program in the summer before the beginning of the student's freshman year. HGR is open to all students but is strongly suggested for students who have lower than MS\&T's average ACT score or a low high school grade point average. Participants live on-campus and partake in classes and activities designed to help them get a positive perspective on college as well as instruction on learning and studying (Missouri University of Science and Technology, n.d.).

While HGR has been in existence since the 1990s, there is no formal study of its effectiveness. Students and faculty have given independent reports that it works; but there has been no formal analysis. Consequently, there is no official data to link student outcomes to HGR participation. According to Datnow, and Park (2014) when data are gathered and analyzed, it can help administrators make informed decisions. Therefore, this study examined the factors that help students feel successful and remain at the university. It also includes descriptive statistics to describe the graduation rate and change in math placement scores among participants. Because students choose to participate in Hit the Ground Running and were not randomly assigned to participate, the descriptive comparisons are not meant to imply a causative relationship. Hopefully this research can provide data for informing institutional decisionmaking about which programs receive resources (Shen, \& Van Cooley, 2008). Not only 
can the results inform this specific university but can contribute to the knowledge base of bridge programs at other universities as well.

When MS\&T established HGR as a pre-college program, this was an effort to help students get a positive start to college. In particular, HGR was an attempt to help students of color, thus increasing their graduation rates. There is a fee to attend HGR, but scholarships are available. The budget for the program is limited, so subsidies are awarded based on a student's math placement score, their ACT score, and their estimated family contribution (EFC) as determined by the Free Application for Federal Student Aid (FAFSA). For example, if a student's test score placed them in Fundamentals of Algebra, they had an EFC of 0, and a low ACT score, they could attend HGR at no cost. Each year, the students who participate differ in their ability and financial need; therefore, the amount given each year depends on the students requesting scholarships. It is important to note that scholarships are not for the high achieving students, but rather are aimed at students who really need extra help in academics and have financial need (R. Morris, personal communication, October 2019).

Missouri University of Science and Technology's overall 6-year graduation rate for all majors, STEM, and non-STEM is $64 \%$. While this graduation rate at MS\&T is above the 59.8\% average rate for four-year public institutions (National Center for Education Statistics, 2018), $36 \%$ of all students who attend Missouri University of Science and Technology do not complete their degree and this has been identified as a cause for concern. Consequently, the administration, faculty, and staff at MS\&T have made increasing retention and graduation rates a goal in the university's strategic plan (Missouri University of Science and Technology Strategic Plan, 2019). Thus, finding methods to help students finish their degrees is an essential part of reaching that goal, and it would be helpful to know whether programs such as HGR are integral to meeting that objective. 
When a student comes to Missouri University of Science and Technology to register for their freshman classes, they take two math placement exams. The scores earned on these tests decide which math class is most appropriate for them. Administering placement tests is common practice for many engineering programs because math is considered a fundamental component of these degree programs (Heiny, Heiny, \& Raymond, 2017; Ngo, \& Kwon, 2015; Sawyer, 2013). However, to help students, the math department at Missouri University of Science and Technology decided that HGR could be used for students to improve their score, thus helping them begin their math sequence at a higher level (R. Morris, personal communication, September 2019). Consequently, HGR decided that if a student's test scores placed them in either pre-algebra or algebra, they were eligible to enroll in a math-intensive track during the summer program. Students attempting to increase their math scores would replace a chemistry unit with an extra math course so they could make the main concentration to improve their math placement score. So, at the end of HGR, the students could retake the math placement test, and if their scores improved, they could move up to the next level of math courses for the fall.

\section{Methodology}

In this study, I used a convergent mixed method design to address the following question: What is the benefit of participating in HGR? I analyzed the qualitative and quantitative data simultaneously. This technique allowed both methods to complement and enhance each other thus providing a deeper understanding of the HGR program (Moseholm \& Fetter, 2017). I combined data from semi-structured interviews with HGR participants and institutional data on previous HGR participants (e.g., high school grades, ACT scores, math placement test scores, enrollment dates, graduation term).

I received a list of 448 students who participated in Hit the Ground Running from the summer of 2014 until summer, 2019 and I sorted the participants into their year of enrollment. . 
The data were from a pre-existing database I received from the Office of Academic Support. Since this design did not provide a control group, the quantitative data offer only descriptive, and not causal, comparisons of program effectiveness. These numbers included high school grade point average (GPA) and ACT scores for all students participating in HGR. It also listed dates of completion and pre and post math placement scores. This method used a purposeful, convenience sampling with the goal of getting a variety of stories from participants (Creswell, 2014). For the qualitative component of the study, semi-structured interviews were conducted with students who completed HGR. It is important to note that the qualitative results are limited to a subsample of students who chose to participate in this program and remained enrolled at the university. .

Table 1: HGR Enrollment by Year

\begin{tabular}{|c|c|c|c|c|c|c|}
\hline Year & 2014 & 2015 & 2016 & 2017 & 2018 & 2019 \\
\hline Students & 60 & 91 & 81 & 75 & 78 & 66 \\
\hline
\end{tabular}

Interviewees were offered a \$20 Amazon gift card for their participation. This payment

served as a way to show my appreciation for taking the time to give an interview. While there is debate regarding the ethical practice of paying people to participate in qualitative research, the general guideline seems to be that if the amount is reasonable, then it is acceptable (Head, 2009). Therefore, the amount chosen was based on the idea that it was a small compensation for the participant but not so large as to be considered coercive.

The semi-structured interviews lasted approximately 30 minutes as this was commonly recommended time limit for interviews (Merriam \& Tisdell, 2017; Seidman, 2013). The interviews were recorded, and written notes were taken as well. Students were free to choose the time of their interview. It is a significant consideration that I conducted interviews primarily in the spring and summer of 2020. Therefore, due to COVID-19, I was unable to interview 
students in person as I had planned. Instead, I amended my IRB application and included the possibility to interview students via Zoom.

When analyzing qualitative data, Merriam and Tisdell (2016) advise data collection and data analysis occur simultaneously. Therefore, as soon as possible after an interview, I transcribed what the participant said. I did this by using both the recording mechanism in Zoom and notes. My written notes included the impressions and observations I had as the student answered questions. After I completed an interview, I summarized what was said, and sent this information via e-mail to each participant to see if my assessment was accurate. If they did suggest some changes, I included these in the analysis. All participants were given pseudonyms.

I also engaged in simultaneous data collection and analysis by reviewing interview transcripts and looked for recurrent themes. This process was done by hand using different color highlighters for each term. As a result of this process, I saw the word friendship or friend in every interview transcript. Once I noticed this in the data, I went back to my interview write-ups and searched for the word "friend," finding that every interview contained some variation of the word friend in response to why they felt HGR was helpful.

My next step in the analysis was to investigate each transcript more closely one by one. This closer scrutiny supported my original finding of the importance of personal connection. Searching for the word friend and related terms helped me recognize when I had enough interviews to conclude the interviews. When starting qualitative data collection, no specific number of participants is unknown at the onset. Instead, the recommendation is to collect responses reach one reaches saturation. Saturation occurs when the students' answers no longer give unique or novel information (Seidman, 2013). Therefore, I ended my data collection after I interviewed 12 participants. 
The participants' time frame included in this study began with students who matriculated at Missouri University of Science and Technology in 2014 and each subsequent year until 2019. The rationale behind looking at this time frame is in line with graduation rates defined by the Integrated Postsecondary Education Data System (IPEDS) classification. Their definition is based on the number of full-time, first-time, degree-seeking students who start and finish at the same institution (IPEDS Glossary, n.d.). Since this study's objective was to discover whether the summer bridge program at Missouri University of Science and Technology was beneficial to participants, I considered the correlation between program participation and key outcomes, such as graduation, ACT scores, and math placement scores.

\section{Limitations}

One of the limitations of this research is that it is almost impossible to randomly assign students to participate in Hit the Ground Running and compare this group to similar students who did not participate. Therefore, the statistical analyses provided were descriptive and cannot imply a causative relationship. Another limitation is that I did not have access to students no longer enrolled at MS\&T. These would be students who participated in HGR but left the university before graduation. While I used these data in the quantitative statistical analysis, I omitted the participants who did not finish their degree from consideration for the interviews because I would not have their contact information. Being able to interview them would add another layer of information. They might provide insights into why they did not remain at the university and if the summer bridge program played any part in their decision. Unfortunately, I cannot interview them, so I could not include their stories. Finally, I was limited in what quantitative data I had access to for use in my analyses. Future research might include additional data on students' demographic and pre-HGR characteristics to be able to observe further dimensions of their experience and how these might change as a result of the program. 


\section{Results}

Descriptive statistics were calculated for various aspects of HGR. For the students participating in HGR from Summer 2014 through Summer 2019, the average ACT score was 27.31. The average grade point average (GPA) was 3.62. I also looked at changes in math placement scores. One of these tests is the Missouri Math Placement Test (MMPT). It is a 40question, multiple choice algebra placement test. The average math placement test score for the first attempt prior to participation was 22.64 and the score on the second attempt was 27.31. For reference, a score of 0-20 puts the student in fundamentals of algebra (Math 1103). If the student scored between 21-23, they are placed in a five-credit college algebra class (Math 1120). Scores in the range of 24-27 enrolled students a three-credit college algebra (Math 1140). If a student earns 28-29, other factors are also considered, and the decision is made whether to put them in Math 1140 or higher. Scores of 30 and up are granted credit Math 1140 (P. Runnion, personal communication, August 25, 2020).

A paired sample t-test was conducted to see if this difference in math placement scores after participating in HGR was significant. There was a significant difference in test scores after students completed the summer program. It is important to note that the data set contained 447 students. Of those participants, 368 had two test scores, both a pre- and post-test score. Students without two test scores were not included in the calculation, thus $17.6 \%$ of the cases were excluded. The reason some students did not have two math placement test scores was due to one of two reasons. In some cases, the student already had a math score that would place them in a math course that was satisfactory for them. Another reason was if the student's major did not require math in its curriculum, the student did not retest. 
Table 1. Math Placement Paired-Sample t-test:

\begin{tabular}{|c|c|c|}
\hline & $\begin{array}{r}\text { Math } \\
\text { Placement Pre- } \\
\text { Test }\end{array}$ & $\begin{array}{r}\text { Math } \\
\text { Placement } \\
\text { Post-Test }\end{array}$ \\
\hline Mean & 22.64 & 27.32 \\
\hline Variance & 30.46 & 20.65 \\
\hline Observations & 368 & 368 \\
\hline Pooled Variance & 25.5529 & \\
\hline Hypothesized Mean Difference & 0.0000 & \\
\hline df & 734.0000 & \\
\hline t Stat & -12.5348 & \\
\hline $\mathrm{P}(\mathrm{T}<=\mathrm{t})$ one-tail & 0.0000 & \\
\hline t Critical one-tail & 1.6469 & \\
\hline $\mathrm{P}(\mathrm{T}<=\mathrm{t})$ two-tail & 0.0000 & \\
\hline t Critical two-tail & 1.9632 & \\
\hline
\end{tabular}

The second test is a trigonometry placement test. This is a 25 -question multiple choice exam. If a student scores between 0 and 14 on this placement test, they do not earn credit for a 2 -creidt trigonometry class (Math 1160). If their score is 15 or greater, they earn credit for Math 1160. A paired sample t-test was also conducted to see if this difference in the trigonometry scores after participating in HGR was significant. The original sample of students contained 447 students, but only 349 had two test scores and were used in the calculation, thus $21.9 \%$ were excluded from the analysis. These results showed a significant difference in test scores upon completion of the summer program. 
Table 2. Trigonometry Paired-Sample t-test

\begin{tabular}{lrr}
\hline & Pre-test & Post-test \\
\hline Mean & 8.6762 & 11.6046 \\
Variance & 11.7656 & 32.5156 \\
Observations & 349 & 349 \\
Pearson Correlation & 0.7070 & \\
Hypothesized Mean Difference & 0.0000 & \\
df & 348.0000 & \\
t Stat & -13.4174 & \\
P(T<=t) one-tail & 0.0000 & \\
t Critical one-tail & 1.6492 & \\
P(T<=t) two-tail & 0.0000 & \\
t Critical two-tail & 1.9668 &
\end{tabular}

Graduation and retention rates were also calculated for some cohorts. The 2014 group was the only one with data to determine a 6-year graduation rate. Of the 59 in that cohort, 39 completed their degree by spring 2020 which is $66 \%$ (Missouri University of Science and Technology, n.d.). This is slightly greater than that reported by the university as a whole which is 64\% (Missouri University of Science and Technology, n.d.). The 5-year graduation rate for the 89 students in the 2015 summer cohort was $57 \%$. This is compared to $53 \%$ five-year graduation rate reported for the university as a whole. On a related note, 64 students participated in the 2019 cohort, and as of spring 2020, $88 \%$ were still enrolled. This is in comparison to $81 \%$ first year retention for the university (Missouri University of Science and Technology, n.d.). To reiterate, the statistics are descriptive only and are not meant to imply HGR plays a causative role in retention or graduation rates.

After analyzing the qualitative data, two major themes emerged: friendship and selfefficacy. I further explored the friendship theme and found some interviewees also used words or phrases like "feeling a connection," a "sense of belonging," "someone to study with," and "people who understood me." All participants said that the people they met during HGR 
were crucial to their college success. Jake said "I do not think I would have stayed at S\&T without HGR - it gave me people to stress out with - get me through..." Another participant, Valerie, noted: "I met my best friend through HGR." Having support was a common theme and appeared in every interview; it was the most frequent answer when I asked what they felt made HGR a success for them.

Another related finding was that various students credited HGR with staying at Missouri University of Science and Technology. In particular, Zachary said, "When I decided engineering was not for me, the reason I stayed was the people I met in HGR...I knew I had the support and I did not want to leave that." This statement directly relates to the importance of connecting with others as this student chose to remain enrolled because of the experience of HGR.

Francine noted the importance of personal connections with professors as well. He credited HGR with learning about people's importance and how it can make a difference between staying and leaving school. William's response illustrated this: "It taught me to talk to professors - through HGR I learned it is OK to reach out to people if you feel alone or overwhelmed. I think that is the key to why I stayed and some other people didn't." This theme of connections with others supports Vygotsky's (1978) view that learning is most effective when it occurs in social interaction.

Another theme that emerged was that of self-efficacy. While participants did not use that phrase, they said they felt more prepared academically and had a sense of familiarity with campus. They said that because of being in the summer program, they began to understand what it would take to succeed. Many noted that HGR was stressful, but they felt it prepared them for what was to come. Several students said they did not feel they studied appropriately in high school and HGR allowed them the opportunity to get a glimpse of the demands when they began their classes. They said that HGR increased their feelings of "being prepared," "feeling ready." 
Some even went further, saying the stress or "shock and awe" they experienced were real positive precursors for their academic performance because they knew what to expect.

Participants described feeling more prepared and capable. Andrew said, "HGR gave me a bridge between high school and college - since I did not have to study in high school, it let me see what college was going to be like." Furthermore, another participant, Luke, said a key factor was the preparatory element of being in a pre-college program: "It helped me feel ready once the craziness (of the semester) begins." Catherine said: "I learned the expectations of S\&T - you can't get by doing the bare minimum."

By having an exposure to the demands of college, these students felt more prepared and self-confident. This can be seen in Justin's reflection:

"I did not have a strong background in math, and HGR let me see how much work it was going to be...I probably would have gotten there eventually once school started, but this was quicker and better. I did not have a negative outcome for my first college test, and that would have been really hard to recover from - but I didn't have to - so that is good." HGR allowed participants to feel more prepared and were ultimately more successful, in their view.

Another interesting observation was a disconnect in why students chose to participate in HGR and what they said helped them the most when they completed it. Almost all participants said they decided to enroll in the summer program because they wanted a head start on their academics - most of them citing that they wanted the opportunity to get a better math placement score. However, even though that was their motivation for registering, no one mentioned math scores when they talked about the key outcomes of participating. In most cases, I had to ask them if they did improve their test scores, and some did not remember if it did or not. 


\section{Discussion}

This study sought to answer the research question: What is the benefit of participating in HGR? The qualitative data results indicated that the program was helpful because students were able to establish relationships and increase their sense of self-efficacy for college success. A review of the literature does suggest that summer bridge programs are useful, but the convergent mixed methods used for this study allowed a look into what makes them effective.

These results provide more evidence that summer bridge programs help retain students, which is an essential emphasis for colleges.

The added element from this work is that I talked directly to students. In doing so, I got an insight into their thoughts and feelings. They articulated precisely what it was that helped them remain at the university. Their stories added to the discussion and highlighted that people and personal connections are vital for students if they want to finish their college degrees. In previous research, Wolf-Wendel, Tuttle, and Keller-Wolfe (1999) found low-ability nonSTEM students had increased self-efficacy after participating in a summer bridge program. My research demonstrated that students in STEM and of varying abilities also benefited from a precollege program. I also used interviews in this study, which allowed me to talk to students about what specifically impacted their experience in HGR.

The fact that math scores increased in this study is also in line with previous research. Doerr, Ørlebìck, and Costello (2014) compared grades after students had an entire semester of mathematics and found those who participated in a summer bridge program earned higher grades than non-participants. HGR students had statistically significant increases in their scores after the three-week course. Hence, this research adds to the idea that improved math performance is a likely outcome of STEM-focused summer bridge programs. 
There were some limitations in this study that can be addressed in future research. One of these drawbacks is that there was no control group with which to compare results. Because HGR is voluntary, it is nearly impossible to randomly assign students to participate and compare them to students who did not participate. However, one could use a comparison group. Comparing participants to a similar group would help further the conclusions from this research. An alternate group to compare outcomes would help establish whether or not HGR was a factor in their retention or if it was a random occurrence.

Another limitation is that I only interviewed students to whom I had access through Missouri University of Science and Technology's e-mail system. Hence, these students were still enrolled or graduated. Interviewing students who did not remain at the university would add another dimension to the study. They might provide perceptions as to why they did not stay, and if the summer bridge program played any part in their decision.

Some suggestions for future studies would be to create a comparison group for quantitative measures using a quasi-experimental design. Having a comparable group could help determine the causative influence of HGR and go beyond describing outcomes. Another idea would be to use a larger sample of students for additional comparisons between participants and non-participants while controlling for some of the key predictors of student success, such as high school grades, college plans and experiences, etc. Since these data exist, descriptive statistics could be run for every cohort that has completed HGR, particularly completion dates. This larger group would be a more comprehensive look at the program and use data for a larger group of participants.

\section{Conclusion}

HGR is an effective program for students attending Missouri University of Science and Technology. The benefit of participating in HGR was suggested by slightly higher 6-year 
graduation and first-year retention rates, although additional research in this area is needed. More importantly, the interviews with past participants revealed that the HGR program is helpful because it allows participants to meet other students and develop friendships, self-efficacy, and realistic academic expectations. Consequently, once classes begin, students have people with whom they can study and turn to for encouragement. These factors were beneficial to students and, in some cases, were the determining reason for whether they should stay, drop out or transfer to another college. Participating in a pre-college program let them understand what was expected of them and allowed them to recognize they were capable and could be successful in college. 


\section{SECTION VI: SCHOLARLY PRACTITIONER REFLECTION}

When I began the Ed.D. program in the summer of 2017, I had no idea how much it would change my life. While I was excited to start the process of earning this degree and knew I would learn a lot about leadership and policy analysis, I was not anticipating how much this program would impact me personally. The entire process, including course work, assignments, and ultimately researching and writing my dissertation-in-practice, has influenced my practice as an educational leader and scholar.

One of the most significant impacts has been my understanding of how data can and should inform decision-making. When I began to consider my dissertation topic, I wanted to investigate something that could help me be a better teacher and advisor to my students. I started this by looking for resources on campus; however, I soon found that while many programs existed, very few had data to support their effectiveness. I learned that critically examining data is in line with what Datnow and Park (2014) recommend in higher education - to pause, reflect, and ask what the institution needs to know to direct resources and have a comprehensive idea of what is beneficial.

An added outcome of the dissertation process and the literature review is that I learned the value of qualitative research. When I first thought about my dissertation in practice, I was sure I would be using a quantitative approach. I knew how to analyze numbers, and I like the precision they provided. However, when I tried to figure out what helped my students, I realized I needed more than quantitative data. I wanted to know what they felt helped them and needed their personal accounts to add a deeper meaning to the numbers. As a result, I plan to continue to utilize qualitative data in my future studies. 
Researching my dissertation and learning throughout the ELPA courses altered how I teach my classes and interact with my students. I now include the topics of privilege and power in every one of my classes. I would describe this experience as transformational (Taylor, 2009) because it created a lasting change in my thoughts, values, emotions, and behaviors. Even though this was not limited to work on my dissertation, it was so significant to me that I wanted to include this in my. I am much more aware that society creates a binary distinction whereby one half is considered superior (Johnson, 2018). I can see that these deep-seated divisions occur in race, gender, religion, socioeconomic status, and other students' characteristics. Before enrolling in this doctoral program, I would not have been as attentive to how these could influence my students, but now I am. I also take more time to get to know my students and be mindful that not everyone had the same start in life, or perhaps they have faced adversity, all of which impact learning. Having a personal connection is one of the ways I work on diversity and inclusion.

Another way my role as an educational leader was influenced is that I understand that I do not have to have all the answers, but instead, I should be open to the skills and input from others. Preskill \& Brookfield (2009) outline the importance of listening to others to be more capable as a leader. In my practice as an educator, one source of input I receive is regular feedback on my teaching. Each semester students evaluate my classes. With my newfound respect for datadriven processes, I will use this information at a different level. Indeed, I will continue to look at the numbers, but I will pay closer attention to student comments and suggestions. It reminds me to put them first, and this is one way to incorporate ethics into my role as a teacher and leader (Stefkovich \& Begley, 2010). Applying what I learn from these reports can help me adopt best practices for them. 
An additional way my practice has been influenced is that I see how higher education is beginning to incorporate accountability standards. This idea is evidenced by Loss and McGuinn (2016) when they propose that these practices that have been an integral part of the K-12 public school system are now becoming more commonplace in colleges and universities. Hence, through my dissertation, I learned the value of using a mixed-methods approach to research. I now understand that numbers can only give part of the picture and that I need to know their stories to understand what they need. My students are complicated, and sometimes an academic setback can escalate, so they no longer feel capable and may leave college (Hibbs, \& Rostain, 2019). Qualitative research can help me answer the question that started this whole process: What do I need to know to help students be successful?"

In conclusion, I can honestly say I am not the same person I was when I began this doctoral program or researching and writing my dissertation. I do not think the same way anymore and have a much more critical understanding of data, research, and how it relates to my practice. Because of the knowledge I acquired, I can analyze situations with a critical eye, and I strive to self-reflect and improve myself as a scholar and an educational leader. 


\section{References}

Alhadabi, A. \& Karpinski, A. C. (2019). Grit, self-efficacy, achievement orientation goals, and academic performance in university students. International Journal of Adolescence and Youth, DOI: 10.1080/02673843.2019.1679202

Ami, C. G. (2001). The effects of a four-week summer bridge program. Albuquerque, NM: University of New Mexico.

Ashley, M., Cooper, K. M., Cala, J. M., \& Brownell, S. E. (2017). Building better bridges into STEM : A synthesis of 25 years of literature on STEM summer bridge programs. $C B E-$ Life Sciences Education, 16(3), 1-18. https://doi.org/10.1187/cbe.17-05-0085

Bandura, A. (1993). Perceived self-efficacy in cognitive development and functioning. Educational Psychologist, 28(2), 117-148.

Bandura, A. (1997). Self-efficacy: The exercise of control. New York: W. H. Freeman.

Bandura, A. \& Jourden, F. I. (1991). Self-regulatory mechanisms governing the impact of social comparison on complex decision making. Journal of Personality and Social Psychology, 60(6), 941-951.

Bardach, E., \& Patashnik, E. M. (2016). A practical guide for policy analysis (5th ed.). Thousand Oaks, CA: CQ Press.

Besterfield-Sacre, M., Altman, C., \& Shuman, L. (1997). Characteristics of freshman engineering students: Models for determining student attrition in engineering. Journal of Engineering Education, 86(2), 139-149.

Bochis, C., Hsia, S., Johnson, P., Boykin, S., Wood, L., Bowen, L, \&Whitaker, K.(2007). Integrated engineering math-based summer bridge program for student retention. American Society for Engineering Education Annual Conference \& Exposition, Honolulu, HI. 
Bolman, L. G., \& Deal, T. E. (2013). Reframing organizations: Artistry, choice, \& leadership (5th ed). San Francisco, CA: Jossey-Bass.

Bolman, L.G., \& Gallos, J.V. (2011). Reframing academic leadership (2nd ed). San Francisco, CA: Jossey-Bass.

Brunner, H. S. (1966). Land-Grant colleges and universities, 1862-1962 Report No. DHEWOE50-030. Office of Education, Washington, D.C. Retrieved from ERIC database (ED167027).

Brunninge, O. (2009). Using history in organizations: How managers make purposeful reference to history in strategy processes. Journal of Organizational Change Management, 22, 8-26. https://doi.org/10.1108/09534810910933889

Bruno, B.C., J.L.K. Wren, K. Noa, E.M. Wood-Charlson, J. Ayau, S. Leon Soon, H. Needham, and C.A. Choy (2016). Summer Bridge program establishes nascent pipeline to expand and diversify Hawai 'i's undergraduate geoscience enrollment. Oceanography, 29(2), 286 - 292. http://dx.doi.org/10.5670/oceanog.201633

Cairncross, C., Jones, S. A., Naegele, Z., \& VanDeGrift, T. (2015). Building a summer bridge program to increase retention and academic success for first-year engineering students. American Society for Engineering Education Annual Conference \& Exposition, Seattle, WA.

Catalfamo, H. (2010). An examination of leadership development in colleges. Educational Planning, 19(4), 8-31.

Chen, X. (2013). STEM attrition: College students' paths into and out of STEM fields (NCES 2014-001). National Center for Education Statistics, Institute of Education Sciences, U.S. Department of Education. Washington, DC.

Christensen, L.O. \& Ridley, J.B. (1983). UM-Rolla: A history of MSM/UMR. 
https://scholarsmine.mst.edu/university_history/3

Citty, J. M., \& Lindner, A. S. (2012). Dual model summer bridge programs: A new consideration for increasing retention rates. American Society for Engineering Education Annual Conference \& Exposition, San Antonio, TX. https://peer.asee.org/21238

Creswell, J. W. (2014). Research design: Qualitative, quantitative, and mixed methods approaches (4th ed.). Thousand Oaks, CA: Sage.

Datnow, A., \& Park, V. (2014). Data-driven leadership. San Francisco, CA: Jossey-Bass.

Diefes-Dux, H. (2002). Does a successful mathematics bridge program make successful students? American Society for Engineering Education Annual Conference \& Exposition, Montreal, Quebec, Canada.

Doerr, H. M., Ørlebìck, J. B., \& Costello, A. (2014). Design and effectiveness of modeling-based mathematics in a summer bridge program. Journal of Engineering Education, 103(1), 92-114. https://doi.org/10.1002/jee.20037

Doubleday, J. (2013, October 7). Earning gap narrows, but college education still pays, report says. The Chronicle of Higher Education. Retrieved from http://chronicle.com

Duckworth, A., \& Quinn, P. D. (2009) Development and validation of the Short Grit Scale (GritS). Journal of Personality Assessment, 91(2), 166-174, DOI:

$10.1080 / 00223890802634290$

Duckworth, A., \& Quinn, P. D. (2009) Development and validation of the Short Grit Scale (GritS). Journal of Personality Assessment, 91(2), 166-174, DOI:

$10.1080 / 00223890802634290$

Elwood, S. A. \& Martin, D. G. (2000). "Placing" interviews: Location and scales of power in qualitative research. The Professional Geographer, 52(4), 649-657. 
Fletcher, S. L. Newell, D. C. Newton, L.D. \&Anderson-Rowland. M. (2001). The WISE Summer Bridge Program: Assessing student attrition, retention, and program effectiveness. American Society for Engineering Education Annual Conference \& Exposition, Albuquerque, NM.

French, R. P., \& Raven, B. (2012). The bases of social power. In J.M. Safritz, J.S. Ott, \& Y.S. Jang (Eds.) Classics of organization theory (6th ed.)(pp. 311-320). Belmont, CA: Wadsworth. (Original Work published in 1959).

Gagliardi, J.S., Parnell, A., \& Carpenter-Hubin, J. (2018). The analytics revolution in higher education: Big data, organizational learning, and student success. Sterling, VA: Stylus.

Geisinger, B. N., \& Raman, R. J. (2013). Why they leave: Understanding student attrition from engineering majors. International Journal of Engineering Education, 29(4), 914 - 925.

George, B. (2003). Authentic leadership: Rediscovering the secrets to creating lasting value. San Francisco: Jossey-Bass.

Gilmer, T. C. (2007). An understanding of the improved grades, retention and graduation rates of STEM majors at the academic investment in math and science (AIMS) program of Bowling Green State University (BGSU), Journal of STEM Education, 8(1), 11-22.

Gleason, J., Boykin, K., Johnson, P., Bowen, L., Whitaker, K., Micu, C. Slappy, C. (2010). Integrated engineering math-based summer bridge program for student retention. Advances in Engineering Education, 2(2), 1-17.

Goldstein, P. J., \& Katz, R. N. (2008). The race between education and technology. Cambridge, MA: The Harvard Press.

Graham, M. J. Frederick, J., Byars-Winston A., Hunter, A., Handelsman, J. (2013). Increasing persistence of college students in STEM. Science, 341(6153), 1455-1456 http://doi.org/10.1126/science.1240487. 
Greenleaf, R. K. (1977). Servant leadership: A journey into the nature of legitimate power and greatness. New York: Paulist Press.

Harkins, M. (2016). Engineering boot camp: A broadly based online summer bridge program for engineering freshmen. American Society for Engineering Education Annual Conference \& Exposition, New Orleans, LA.

Hausfather, S. J. (1996). Vygotsky and schooling: Creating a social context for learning. Action in Teacher Education, 18 (2), 1-10, doi 10.1080/01626620.1996.10462828

Head, E. (2009). The ethics and implications of paying participants in qualitative research. International Journal of Social Research Methodology, 12(4), 335-344, DOI: $10.1080 / 13645570802246724$.

Heifetz, R.A. (1994). Leadership without easy answers. Cambridge, MA: Belknap Press.

Heifetz, R., \& Laurie, D. L. (2011). The work of leadership. In HBR's 10 must reads on leadership (pp. 57-78), Boston, MA: Harvard Business Review Press. (Reprint R0111K, Originally published in January 1997).

Heiny, R. L. Heiny, E. L., \& Raymond, K. (2017). Placement model for first-time freshmen in calculus I (Math 131): University of Northern Colorado. Journal of College Student Retention: Research, Theory \& Practice, 19(3) 270-283. doi: $10.1177 / 1521025115618491$

Hersey, P., \& Blanchard, K. H. (1969). Life-cycle theory of leadership. Training and Development Journal, 23, 26-34.

Hibbs, J., \& Rostain, A. (2019). The stressed years of their lives: Helping your kid survive and thrive during their college years. New York, NY: St. Martin Press. 
Hilgoe, E., Brinkley, J., Hattingh, J., \& Bernhardt, R (2016). Effectiveness of the North Carolina early mathematics placement test in preparing high school students for college-level introductory mathematics courses. College Student Journal, 50(3), 369-378.

Hummer, R. A., \& Hernandez, E. M. (2013). The effect of educational attainment on adult mortality in the United States. Population Bulletin, 68(1), 1-16.

IPEDS Glossary (n.d.). Retrieved from: https://surveys.nces.ed.gov/ipeds/VisGlossaryAll.aspx

IPEDS (n.d.). Making the cut: Who meets highly selective college entrance criteria? Retrieved from https://nces.ed.gov/pubs/web/95732.asp

Jansson, N. (2013). Organizational change as practice: A critical analysis. Journal of Organizational Change Management, 26(6), 1003-1019.

Johnson, A.G. (2018). Privilege, power and difference (3rd ed). New York, NY: McGraw Hill. Jones, W. A., \& Braxton, J.M. (2010). Cataloging and comparing institutional efforts to increase student retention rates. Journal of College Student Retention, 11(1), 123-139.

Kallison, J. M. \& Stader, D. L. (2012). Effectiveness of summer bridge programs in enhancing college readiness. Community College Journal of Research and Practice, 36, 340-357.

King, D., \& Masterson, L. (2011). Summer bridge program: A jumpstart for engineering students. AC 2011-915. Paper presented at American Society for Engineering Education. Arkansas Tech University, Russellville, Arkansas.

Kokkelenberg, E. C., \& Sinha, E. (2010). Economics of education review who succeeds in STEM studies? An analysis of Binghamton University undergraduate students. Economics of Education Review, 29(6), 935-946. https://doi.org/10.1016/j.econedurev.2010.06.016

Kopec, R. L., \& Blair, D. A. (2014). Community for Achievement in Science, Academics, and Research: The CASAR Project. 6th Annual First Year Engineering Experience 
Conference, College Station, TX

Kowalchuk, R. Green, T. Ricks, R. \& Nicklow. J. (2010). Evaluation of a summer bridge program on engineering students' persistence and success. American Society for Engineering Education Annual Conference \& Exposition, Louisville, KY.

Kotter, J. P. (1990). A force for change: How leadership differs from management. New York: Free Press.

Kowalchuk, R. Green, T. Ricks, R. \& Nicklow. J. (2010). Evaluation of a summer bridge program on engineering students' persistence and success. American Society for Engineering Education Annual Conference \& Exposition, Louisville, KY.

Levi. G. (2017). Group dynamics for teams (5th ed.). Thousand Oaks, CA: Sage.

Loss, C. P., \& McGuinn, P. J. (Eds.). (2016). The convergence of $K-12$ and higher education: Policies and programs in a changing era. Cambridge, MA: Harvard Education Press.

Manning, K. (2013). Organizational theory in higher education. New York, NY: Routledge.

Maton, K. I., Beason, T. S., Godsay, S., Domingo, M. R. S., Bailey, T. C., Sun, S., \& Hrabowski, F. A. III. (2016). Outcomes and processes in the Meyerhoff Scholars Program: STEM $\mathrm{PhD}$ completion, sense of community, perceived program benefit, science identity, and research self-efficacy. CBE_Life Sciences Education, 15(3), ar48. http://dx.doi.org/10.1187/ cbe.16-01-0062.

McCurrie, M. K. (2009). Measuring success in summer bridge programs: Retention efforts and basic writing. Journal of Basic Writing, 28, 28-49.

Merriam, S. B., \& Tisdell, E. J. (2016). Qualitative research: A guide to design and implementation (4th ed.). San Francisco, CA: Jossey-Bass.

Mihelic, K.K, Lipicnik, B. \& Tekavcic, M (2010). Ethical leadership. International Journal of Management and Information Systems, 14 (5), 31-41. 
Missouri University of Science and Technology (n.d.). Academic programs. Retrieved from https://mst.edu/academic-programs/

Missouri University of Science and Technology (n.d.).Faculty Senate. Retrieved from https://facultysenate.mst.edu

Missouri University of Science and Technology (n.d.). Hit the Ground Running (HGR). Retrieved from https://academicsupport.mst.edu/hgr/

Missouri University of Science and Technology (n.d.). Institutional Research and Data Research.https://data.mst.edu/media/administrative/data/documents/ factsheet/2017factsheet/Retention_Graduation_Report2017_fnl.pdf

Missouri University of Science and Technology (2019). Missouri S\&T Strategic Plan (2019) https://provost.mst.edu/media/administrative/provost/documents/missouricompact/Strateg ic\%20Plan\%202019_September.pdf

Missouri University of Science and Technology (n.d.). Program and degree data. Retrieved from https://data.mst.edu/program-degree-data/

Missouri University of Science and Technology (2016). Student success committee 2015-2016 annual report. Retrieved from https://facultysenate.mst.edu/media/campussupport/facultysenate/ documents/specialcomittees/Student\%20Success\%20Annual\%20Report\%20201516.pdf\#170814021438

Moseholm, E., \& Fetter, M.D. (2017). Conceptual models to guide integration during analysis in convergent mixed methods studies. Methodological Innovations, 10(2), 1-11. https://doi.org/10.1177/2059799117703118 
Murphy, T. E., Gaughan, M., Hume, R., \& Moore, S. G. (2010). College graduation rates for minority students in a selective technical university: Will participation in a summer bridge program contribute to success? Educational Evaluation and Policy Analysis, 32(1), 70-83. https://doi.org/10.3102/0162373709360064

Murray, S. L., Dukes, S. \& Weidner, N. (2018). Improving first-year STEM students' performance and retention: Is grit the answer? Quality Approaches in Education, 9 (2), $12-16$.

MyMajors.com (2019). Retrieved from https://www.mymajors.com/college-majors/

National Academies of Sciences, Engineering, and Medicine (2016). Barriers and opportunities for 2-year and 4-year STEM degrees: Systematic change to support diverse student pathways. Committee on Barriers and Opportunities in Completing 2-Year and 4-Year STEM degrees. (S. Malcom \& M. Feder, Eds.). Washington, DC: The National Academies Press. https://doi.org/10.17226/21739

National Academies of Science, Engineering and Medicine (2018). Graduate STEM education for the 21st century. Retrieved from http://www8.nationalacademies.org/ onpinews/newsitem.aspx ?RecordID $=25038$

National Center for Education Statistics. (2018). The Condition of Education 2018 (NCES 2018144), Undergraduate retention rates. Retrieved from https://nces.ed.gov/fastfacts/display.asp?id=40.

National Science Board (2018). Science and Engineering Indicators 2018. NSB-2018-1. Alexandria, VA: National Science Foundation. https://www.nsf.gov/statistics/indicators/. Ngo, F., \& Kwon, W. W. (2015). Using multiple measures to make math placement decisions: Implications for access and success in community colleges. Journal of College Student Retention, 56(5), 442-470. https://doi.org/10.1007/s11162-014-9352-9 
Nite, S.B., Caprano, R.M., Caprano, M.D., Allen, G.D., Pilant, M., \& Morgan, J (2015). A bridge to engineering: A personalized precalculus (bridge) program. In $45^{\text {th }}$ Annual Frontiers in Education Conference. Proceedings of the 2015 IEEE Frontiers in Education Conference https://doi.org/10.1109/FIE.2015.7344358

Northouse, P.G. (2016). Leadership: Theory and practice (7th ed). Los Angeles, CA: SAGE.

Pascarella, E. T., \& Terenzini, P. T. (1991). How college affects students: Finding insights from twenty years of research. San Francisco, CA: Jossey-Bass.

Persaud, A., \& Freeman, A. L. (2005). Creating a successful model for minority students' success in engineering: The PREF Summer Bridge Program. Women in Engineering ProActive Network/National Association of Multicultural Engineering Program Advocates Joint Conference, Las Vegas, NV (pp. 1-7).

Preskill, S., \& Brookfield, S. D. (2009). Learning as a way of leading: Lessons from the struggle for social justice. San Francisco, CA: John Wiley \& Sons.

Pusser \& Marinson (2012). The elephant in the room: Power, politics and global rankings in higher education. In M.N. Bastedo (Ed) The organization of higher education: Managing colleges for a new era. Baltimore, MD: The Johns Hopkins University Press.

Quiroz, A. G. \& Garza, N. R. (2018). Focus on student success: Components for effective summer bridge programs. Journal of Hispanic Higher Education, 17(2) 101 -11. doi.org/10.1177/1538192717753988.

Raines, J.M. (2012). FirstSTEP: A preliminary review of the effects of a summer bridge program on pre-college STEM majors. Journal of STEM Education, 13(1), 22-30.

Ravitch, R. M., \& Riggan, M. (2012). Reason \& rigor: How conceptual frameworks guide research. Los Angeles, CA: Sage Publishing. 
Reisel, J. R. Jablonski, M., Hosseini, H, \& Munson, E. (2012). Assessment of factors impacting success for incoming college engineering students in a summer bridge program. International Journal of Mathematical Education in Science and Technology, 43(3), 421433. doi.org/10.1080/0020739X.2011.618560

Relles, S. R., \& Tierney, W. G. (2014). The summer before series findings from 10 years of a summer bridge program. Pullias Center for Higher Education, Rossier School of Education, University of Southern California (ERIC Document No. ED 562034)

Rothwell, J. (2013). The hidden STEM economy. Metropolitan Policy Program at Brookings

Rubin, D. B. (1974). Estimating causal effects of treatments in randomized and nonrandomized studies. Journal of Educational Psychology, 66(5), 688-701.

Russell, M. L., \& Atwater, M. M. (2005). Traveling the road to success: A discourse on persistence throughout the science pipeline with African American students at a predominantly White institution. Journal of Research in Science Teaching, 42(6), 691715.

Russomanno, D., Best, R., Ivey, S., Haddock, J. R., Franceschetti, D., Hairston, R. J., ... Dydlodeoh, Z. (2010). MemphiSTEP: A STEM talent expansion program at the University of Memphis. Journal of STEM Education Volume, 11(1), 69-82.

Rull, V. (2014). The most important application of science: As scientists have to justify research funding with potential social benefits, they may well add education to the list. $E M B O$ Reports, 15(9), 919-922. doi:10.15252/embr.201438848

Sablan, J. R. (2014). The challenge of summer bridge programs. American Behavioral Scientist, 58(8), 1035-1050. https://doi.org/10.1177/0002764213515234

Saltzman, G. M. (2011). Beyond academic freedom: The economic case for tenure. The NEA 2018 Almanac of Higher Education. 19-31. 
Sawyer, R. (2013). Beyond correlations: Usefulness of high school GPA and test scores in making college admissions decisions. Applied Measurement in Education, 26(2), 89-112.

Schneider, M., \& Yin, L . (2011). The high cost of low graduation rates: How much does dropping out of college really cost? Washington, DC: American Institutes for Research American.

Schein, E. H. (1993). Defining organizational culture. In J.M. Safritz, J.S. Ott, \& Y.S. Jang (Eds) Classics of organization theory (6th ed., pp. 360-367). Belmont, CA: Wadsworth. (Original work published 1993).

Schilling, J. (2009). From ineffectiveness to destruction: A qualitative study on the meaning of negative leadership. Leadership, 5(1), 102-128.

Seidman, I. (2012). Interviewing as qualitative research: A guide for researchers in education and the social sciences (4th ed.). New York, NY: Teachers College Press.

Shapiro, J. P., \& Stefkovich, J. A. (2016). Ethical leadership and decision making in education: Applying theoretical perspectives to complex dilemmas (4th ed). New York: NY: Routledge.

Shen, J \& Van E. Cooley, V. E. (2008). Critical issues in using data for decision-making. International Journal of Leadership in Education, 11(3), 319-329. DOI: $10.1080 / 00461520.2012 .667064$

Strayhorn, T. L. (2011). Bridging the pipeline: Increasing underrepresented students' preparation for college through a summer bridge program. American Behavioral Scientist, 55(2), 142-159. doi:10.1177/0002764210381871 
Stefkovich, J., \& Begley, P.T. (2012). Ethical school leadership: Defining the best interests of students. Educational Management Administration \& Leadership, 35(2), 205-224. doi: 10.1177/1741143207075389.

Storey, V., Caskey, M. Hesbol, K., Marshall, J., Maughan, B., \& Dolan, A. (2015). Examining EdD dissertations in practice: The Carnegie Project on the education doctorate. International Higher Education Teaching and Learning Association, 5, Retrieved from https://www.hetl.org/examining-edd-dissertations-in-practice-the-carnegie-project-ontheeducation-doctorate/

Taylor, E.W. (2009). Fostering transformative learning. In J. Mezirow, E.W. Taylor \& Associates (Eds.) Transformative learning in practice: Insights from community, workplace, and higher education (pp.3-17). San Francisco, CA: John Wiley \& Sons.

Thompson, J. A. (1999). Enhancing cognitive development in college classrooms: A review. Journal of Instructional Psychology, 26(1), 56-63.

Tomasko, D. L., Ridgway, J. S., Olesik, S. V, Waller, R. J., Mcgee, M. M., Barclay, L. A., Upton, J. (2013). Impact of summer bridge programs on STEM retention at The Ohio State. American Society for Engineering Education Annual Conference \& Exposition, Columbus, $\mathrm{OH}$.

Tomasko, D. L., Ridgway, J. S., Waller, R. J., \& Olesik, S. V. (2016). Association of summer bridge program outcomes with STEM retention of targeted demographic groups. Journal of College Science Teaching, 45(4), 90-99.

Tracy, S. J. (2010). Qualitative quality: Eight "big-tent" criteria for excellent qualitative research. Qualitative Inquiry, 16 (10), 837 - 851. doi:10.1177/1077800410383121

University of North Carolina at Chapel Hill (n.d.). UNC Summer Bridge. Retrieved from http://summerbridge.unc.edu/ 
U.S. Department of Education, Institute of Education Sciences (2016) What Works

Clearinghouse. Supporting postsecondary success intervention report: Summer bridge programs. Retrieved from http:// ies.ed.gov/ncee/wwc/Doc/ InterventionReport/ wwc_summerbridge_071916.pdf.

Varde, K. S. (2004). Effects of pre-freshman program for minority students in engineering, American Society for Engineering Education Annual Conference \& Exposition, Salt Lake City, UT.

Vedder, R. (2018). Benefits of college by degrees. Computer Education, 51, 96-99. https://doi.org/10.1109/MC.2018.2701646

Vygotsky, L.S. (1978). Mind in society. Cambridge, MA: Harvard University Press

Walpole, M., Simmerman, H., Mack, C., Mills, J. T., Scales, M., \& Albano, D. (2008). Bridge to success: Insight into summer bridge program students' college transition. Journal of the First-Year Experience \& Students in Transition, 20(1), 11-30.

Wathington, H., Pretlow, J \& Barnett, E. (2009). A good start? The impact of Texas' developmental summer bridge program on student success. The Journal of Higher Education 87(2), 1-29.

Wheatland, J. A. (2002). Factors that affect grade point average and retention status of first-time science, engineering, and mathematics students at Morgan State University, a Historically Black University. American Society for Engineering Education Conference. Montreal, Canada.

Wheeler, E. R. \& Wischusen, S. M. (2014). Developing self-regulation and self-efficacy: A cognitive mechanism behind the success of biology boot camps. Journal of Science Education, 18(1), 1-6. 
Windsor, A., Russomanno, D. J., Bargagliotti, A., Best, R., Franceschetti, D., Haddock, J., \& Ivey, S. (2015). Increasing retention in STEM: Results from a STEM talent expansion program at the University of Memphis. Journal of STEM Education: Innovations and Research, 16(2), 11-19.

Wolf-Wendel, L. E., Tuttle, K., \& Keller-Wolfe, C. M. (1999). Assessment of a freshman summer transition program in an open-admissions institution. Journal of the First-Year Experience \& Students in Transition, 11(2), 7-32.

Wood, R., \& Bandura, A. (1989). Impact of conceptions of ability on self-regulatory mechanisms and complex decision making. Journal of Personality and Social Psychology, 56, 407-415.

York, T. T., Gibson, C., Rankin, S. (2015). Defining and measuring academic success. Practical Assessment, Research \& Evaluation, 20(5), 1-21. Retrieved from http://pareonline.net/getvn.asp?v=20\&n=5. 
Appendix A: Questions for Interview:

Thank the interviewee for spending time with me and answering questions.

Reintroduce self and reiterate purpose of research: I would like to see what factors contribute to student retention/success at Missouri University of Science and Technology. In particular I want to see what it is about participation in HGR that may help students be successful.

I would like to assure you that I will do my best to keep your responses confidential. With your permission, I would like to audio tape the interview. After our session is complete I will write down what you have said. However, I will not use your name or provide information that could identify you. All the information will be presented in general terms.

Also - please be assured that during the interview if for any reason you do not want to answer a question, you are not obligated to do so - may I please have your verbal permission to interview you?

Purpose - I want to hear your story

Please tell me how you got here? Why MS\&T?

I understand you participated in Hit the Ground Running, can you tell me more about it?

How did you learn about HGR?

What motivated you to enroll?

Please tell me all you remember about HGR?

Suppose I (or another incoming freshman) knew nothing about the program, what would you tell me (them) about it?

In what ways did HGR impact you and your thoughts about - yourself? College? Future plans?...

Please tell me all about your freshman year of college? (or subsequent years if older student)

What else would you like to share about HGR or your college experience? 
Hello Student,

Appendix B: Email Script for Recruitment:

My name is Merilee Krueger, and I am conducting a research study on the impact of Hit the Ground Running (HGR). I am contacting you because you participated in the program (insert date of participation). As part of the research process, I would like to ask you some questions about your experience in the program. Your participation in this research is completely voluntary. If you choose to participate, the interview will last approximately thirty minutes and you will receive a \$20 Amazon gift card for participating.

Due to the restrictions on campus for COVID-19, the interview will take place using Zoom at your convenience.

If you would like to participate or have further questions, please contact me. My e-mail address is krueger@mst.edu and my phone number is (573) 341-7244. Thank you.

Sincerely,

Merilee A. Krueger

Teaching Professor

Missouri S\&T

Department of Psychological Science

HSS 112

Rolla, MO 65409 


\section{Appendix C}

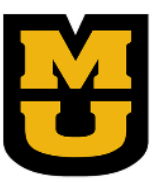

Institutional Review Board

482 McReynolds Hall

University of Missouri-Columbia

Columbia, MO 65211

FWA Number: 00002876

573-882-3181

IRB Registration Numbers: 00000731, 00009014

irb@missouri.edu

April 10, 2020

Principal Investigator: Merilee Krueger

Department: Psychological Science

Your Exempt Amendment Form v.2 to project entitled AN EXAMINATION OF THE IMPACT OF A

PRECOLLEGE PROGRAM ON COLLEGE SUCCESS was reviewed and approved by the MU Institutional Review Board according to the terms and conditions described below:

$\begin{array}{ll}\text { IRB Project Number } & 2020266 \\ \text { IRB Review Number } & 263334 \\ \text { Initial Application Approval Date } & \text { March 19, 2020 } \\ \text { Approval Date of this Review } & \text { April 10, 2020 } \\ \text { IRB Expiration Date } & \text { March 19, 2021 } \\ \text { Level of Review } & \text { Exempt } \\ \text { Project Status } & \text { Active - Open to Enrollment }\end{array}$

Exempt Categories (Revised Common Rule) 45 CFR 46.104d(1)

Risk Level Minimal Risk

The principal investigator (PI) is responsible for all aspects and conduct of this study. The PI must comply with the following conditions of the approval:

1. Enrollment and study related procedures must remain in compliance with the University of Missouri regulations related to interaction with human participants following guidance at https://research.missouri.edu/about/covid-19-info.php.

2. No subjects may be involved in any study procedure prior to the IRB approval date or after the expiration date.

3. All changes must be IRB approved prior to implementation utilizing the Exempt Amendment Form.

4. The Annual Exempt Form must be submitted to the IRB for review and approval at least 30 days prior to the project expiration date to keep the study active or to close it.

5. Maintain all research records for a period of seven years from the project completion date. 
If you are offering subject payments and would like more information about research participant payments, please click here to view the MU Business Policy and Procedure: http:// bppm.missouri.edu/chapter2/2_250.html

If you have any questions or concerns, please contact the MU IRB Office at 573-882-3181 or email to muresearchirb@missouri.edu.

Thank you,

MU Institutional Review 


\section{Appendix D}

MISSOURI

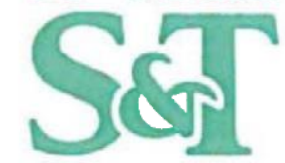

March 6, 2020

An equal opportuntty institution

\section{Office of Academic Support}

105 Norwood Hall | 320 W. $12^{\text {th }}$ St. | Rolla, MO 65409

573-341-7276 | academicsupport@mst.edu | www.academicsupport.mst.edu

To whom it may concern:

Merilee Krueger is a doctoral student with the ELPA Statewide Cooperative Program at Mizzou. During her research and dissertation process, she has talked with me concerning programming that I oversee here at Missouri S\&T. She will require specific information/data that I can provide to her. This letter is to let you know that I am willing and able to provide Merilee information/data for her research and dissertation process concerning my programs.

Please let me know if you have any questions.

Sincerely,

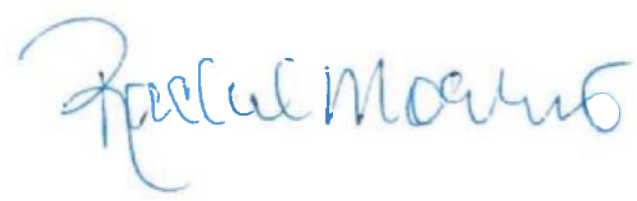

\section{Rachel K Morris, M.Ed.}

Assistant Vice Provost for Student Support

rachelm@mst.edu

573-341-7600 


\section{Appendix E}

\section{JUNE २०18}

ORGANIZATIONAL CHART

Chancellor

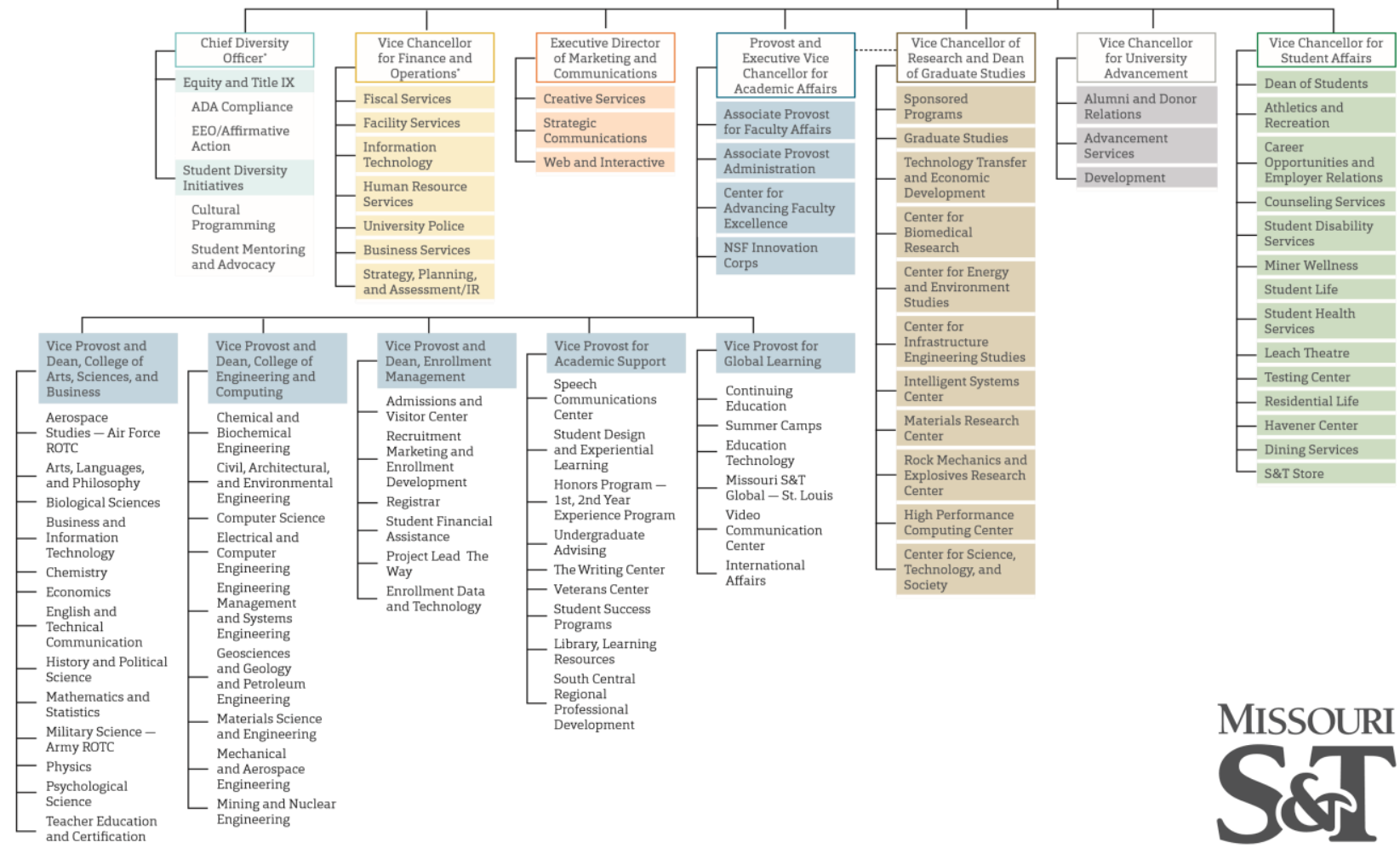




\section{Vita}

The author of this study, Merilee A. Krueger, is from a long line of educators. Her great grandmother, Anna Krueger, was one of the first women to graduate from Northern State Teacher's College with a teaching degree. Her grandmother, father, and sister all earned teaching credentials there as well. Merilee began her pursuit of higher education in 1981 at Creighton University in Omaha, Nebraska, and graduated with a Bachelor of Arts degree in 1985. She then went on to earn a Master of Arts degree in Cognitive Developmental Psychology from the University of Nebraska in 1990.

Merilee started teaching at the University of Missouri - Rolla (now known as Missouri University of Science and Technology) as an adjunct instructor in psychology in 1990. She continued teaching in the psychology department and took a non-tenure track position in 2009. She was promoted to a full teaching professor in 2019 and is still teaching and advising in psychological science.

It was a lifelong dream of Merilee's to earn a doctorate. Therefore, when her youngest son graduated from high school in 2017, she began the Educational Leadership and Policy Analysis doctoral program at the University of Missouri - Columbia. She was a member of Cohort 11 and attended class in Jefferson City. 